\title{
TEORÍAS DE LA DEMOCRACIA Y FUNDAMENTACIONES DE LA DEMOCRACIA
}

\section{Introducción}

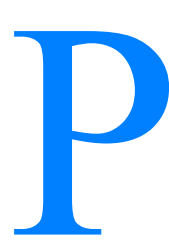

arece que la democracia es buena cosa. Parece, también, que no está muy claro por qué. Si un politólogo del futuro o de otro planeta, ingenuo e inteligente (los convenientes atributos de tales invitados), llegada la ocasión, entretuviera sus horas en repasar nuestras alabanzas, no podría por menos que mirar con cierta ternura nuestra pasión por la democracia y con desconfianza nuestras explicaciones. «Desde luego -pensaría- todos la querían, aunque cada uno por razón distinta, razón que, además, era discutida por el vecino. Quienes elogiaban sus virtudes para recoger la voluntad colectiva se encontraban con sofisticados teoremas que mostraban la imposibilidad de traducir inequívocamente muchas voluntades en una voluntad colectiva o con prudentes réplicas que recordaban que los representantes políticos difícilmente están en condiciones de atender a sus representados; quienes apreciaban sus virtudes educativas sobre la ciudadanía no podían desatender sin deshonestidad una investigación empírica que revelaba la pobre atención hacia lo público de sus presuntos protagonistas, los ciudadanos de las modernas democracias. Algunos se acordaban de la estabilidad social, el progreso económico, la justicia o corrección de las decisiones democráticas y de mil cosas más. Inmediatamente, otros tantos replicaban con contraejemplos a cada uno de esos motivos. En fin, demasiadas razones y demasiado frágiles». A buen seguro, nuestro confundido investigador no podría por menos que concluir que el acuerdo acerca de la bondad de la democracia era de vuelo corto, que los fundamentos morales de la democracia no estaban claros ${ }^{1}$.

Si llegaran a sus manos, las siguientes páginas quisieran oficiar como una invitación a que ocupe su tiempo en menesteres más provechosos: el

${ }^{1}$ Para exploraciones generales y comparaciones de distintas estrategias de fundamentación cfr. Dahl (1989); Gutmann (1993); Nelson (1980); Garzón Valdés (1994); Nino (1991); Ackerman, Rosenkrantz (1991); Macpherson (1980); Habermas (1992). 
problema de los fundamentos morales no tiene solución en tanto los disputantes están manejando diferentes ideas de democracia y diferentes ideas de fundamentación ${ }^{2}$; y, claro, sihay diferencias en lo que se fundamenta y en cómo se fundamenta, difícil será resolver «el problema de la fundamentación». También quisieran prevenirlo contra cualquier intento de empeñarse en solucionar el problema: no hay manera. La dificultad no es circunstancial, sino esencial. A diferencia de lo que sucede con otras fundamentaciones morales, la fundamentación de la democracia exige una teoría de la democracia, que permita reconocer qué estamos fundamentando, y esa misma teoría impone una diferencia en el procedimiento de fundamentación $n^{3}$. Las páginas que siguen mitigarán el dogmático hermetismo de este diagnóstico ${ }^{4}$. De momento baste con abundar en lo dicho: Las diferentes estrategias

2 A lo largo del texto se distinguirá entre «fundamentaciones de la democracia» y «teorías de la democracia». Vale la pena precisar el sentido de esa distinción. El asunto central que nos ocupará, la «fundamentación», se refiere a las justificaciones normativas, a «por qué es buena la democracia». La teoría se entiende en su sentido más estricto y común en filosofía de la ciencia: un conjunto de enunciados (leyes) que conjuntamente constituyen una definición. Desde el punto de vista positivo, interesan las teorías -definiciones- que encuentran referentes. De todos modos, una teoría que no tiene «modelos», sistemas reales, en los que «se realice», puede resultar interesante para propósitos normativos o analíticos. Así se podría decir que las democracias contemporáneas no son modelos de la teoría de la democracia republicana (en realidad, la crítica reaccionaria $a$ la Carl Schmit, Mosca, Pareto o Michels no hacía sino percibir imprecisamente esta circunstancia: se critica como falsa democracia -republicana- lo que de hecho es -un sistema de- una democracia diferente, un modelo de otra teoría: la democracia competitiva). Junto a las dos dimensiones mencionadas, «fundamentación» y "teoría», habría que añadir la «ontología social», entendiendo por tal una serie de tesis acerca del -para decirlo clásicamente- ser social que acompañan a fundamentaciones y teorizaciones. Así por ejemplo, la teoría de la democracia como un mercado presume un mundo social compuesto por homine oeconomici, por individuos que persiguen sus intereses (Ovejero, 1995a).

También debe distinguirse la idea de fundamentación normativa en el sentido aquí utilizado de la idea de fundamentación -más exigente- que acompaña a la evaluación de los proyectos políticos de cierta hondura. En este último caso se requiere no sólo la vertebración normativa con los valores, con el ideario inspirador, sino también la compatibilidad con el conocimiento teórico disponible, la realizabilidad práctica y la estabilidad reproductiva. Sobre estos aspectos cfr. Ovejero 1995a.

3 Implícitamente se está presumiendo aquí un compromiso entre método y teoría que requiere algunas precisiones. Desde luego: a) la distinción conceptual es clara, una cosa es qué explica (teoría) y otra cómo se explica (método); b) distintas teorías pueden compartir un mismo procedimiento explicativo (p.e. la explicación funcional presente en marxistas y funcionalistas); c) en principio una misma teoría puede adoptar -aunque resulta difícil pensar que no se requiera un ajuste categorial- distintos formatos explicativos. (Así ha sucedido con la teoría neoclásica del equilibrio general neoclásico y la teoría de la explotación marxista que han encontrado diferentes formulaciones matemáticas). Pero no es menos cierto que las teorías constriñen el ámbito de los procedimientos de explicación: el qué explica limita en buena medida el cómo se explica. Por ejemplo, no se ve el modo en el que las teorías físicas contemporáneas podrían adoptar un formato intencional o funcional.

${ }^{4}$ Diagnóstico que vale sobre todo para la que aquí se llamará fundamentación instrumental. El esqueleto argumental se puede anticipar sumariamente: a) fundamentar requiere reconocer que se fundamenta, $\mathrm{x}$; b) reconocer $\mathrm{x}$ requiere una teoría sobre $\mathrm{x}$ (al modo como la teoría atómica permite identificar a los átomos); c) una teoría establece -al menos- una relación -un vínculo causal, p.e.- entre dos entidades (p.e.: «la democracia es un sistema que permite maximizar el bienestar»), entre «x e $\mathrm{y} » ; \mathrm{d}$ ) esa relación es, a la vez, una pieza de la fundamentación («x se justifica por y»). Por tanto, la teoría, que es una estipulación acerca de aquello sobre lo que recae, es también la premisa que garantiza la fundamentación. Por ejemplo, el juicio «la democracia es un sistema que al expresar las preferencias permite maximizar el bienestar», sirve para estipular, reconocer y fundamentar la democracia. Si no se expresan las preferencias (y se maximiza el bienestar) no estamos ante una democracia y la democracia se justifica precisamente porque -en ella- se expresan las preferencias (y se maximiza el bienestar).

La necesidad de una teoría que permite saber qué es lo que se fundamenta se hace más manifiesta cuando nos encontramos frente a procesos complejos en los que no hay un reconocimiento independiente, desde «fuera de la teoría», de lo que se está fundamentando. Es lo que sucede con el mercado (Ovejero, 1994a). Con todos los matices, esa circunstancia no concurre cuando se trata de derechos específicos acerca de cuya caracterización no hay problema: los derechos al voto, a la ciudadanía, la eutanasia, de los animales, etc. 
de fundamentación manejan diferentes ideas de democracia y diferentes ideas acerca de lo que se entiende por una correcta justificación.

La primera parte de la exposición se ocupará de justificar la naturaleza del problema de la fundamentación moral de la democracia (PFD en lo sucesivo). Me referiré a tres enfoques diferentes que abarcan las distintas maneras de abordar la fundamentación (instrumental (FI), histórico (FH) y epistémico (FE)), cada uno de ellos asociados a diferentes teorías de la democracia: competitiva, comunitaria y republicana. Por más que en la vecindad de las diferentes perspectivas se puedan reconocer sin esfuerzo diferentes corrientes de la filosofía política contemporánea, debe advertirse que el criterio discriminador es prioritariamente metodológico, que se refiere sobre todo a procedimientos, no a tesis sustantivas ${ }^{5}$. De hecho, cada una de las

${ }^{5}$ Por lo demás, la reconstrucción traicionará un poco a todo el mundo, pero eso hay que atribuirlo, además de a las ignorancias del traidor, a la falta de anatomías teóricas claras y distintas en la obra de los traicionados. Incluso el utilitarismo, tantas veces presentado como ejemplo de teoría normativa precisa, está cargado de ambigüedades empezando por la propia noción de utilidad. Las ideas sobre utilidad son bien diversas: como satisfacción de deseos; como bienestar recibido; como elecciones realizadas; como sustancia; como propiedad última a la que se reducen las demás. Cada una de las ideas se asocia a un asunto distinto y, en ocasiones, a una métrica diferente. En particular las ideas que se manejan en teoría económica, en teoría de juegos y en teoría moral son diferentes. Estas cosas conviene recordarlas, entre otras razones porque las críticas a las -muchas- debilidades del utilitarismo -indistinción entre personas, derechos, etc.- empiezan por concederle un crédito para el que no tiene avales. Avales que, por cierto, son particularmente necesarios para una teoría consecuencialista: si se juega a evaluar por los resultados, comparando sus eficiencias, hay que estar en condiciones de especificar las funciones métricas, hay que poder echar las cuentas ( $\mathrm{y}$, también, disponer de las teorías que nos relacionen acciones y consecuencias: vamos, un sueño). De otro modo, nos encontramos, amén de con la falta de nervio intelectual propia de las simplificaciones pseudocientíficas, con una «ilusión de rigor», conocida falacia que resulta particularmente deshonesta cuando se acompaña -como sucede con frecuencia con los utilitaristas- de condenas a los rivales «poco operacionales», «especulativos», etc.

Curiosamente parece que todos confían en que «los economistas tengan claro qué sea eso de la utilidad». Y lo cierto es que entre éstos, los que realmente saben del asunto confiesan que los economistas no lo tienen claro (Sen, 1991: 278). En el caso de la teoría normativa, en el utilitarismo, las cosas son mucho más graves que en la teoría económica. Esta necesita una idea de utilidad (ordinal) muy pobre, muy elemental, para -al menos- construir su caja de herramientas. Por contra, el utilitarismo necesita una idea fuerte de utilidad, que incluya la posibilidad de comparaciones interpersonales de utilidad. El problema es que, sin eso, el utilitarismo no es nada, y eso es imposible (Haussman, 1995). Cfr. infra nota 25. 
estrategias de fundamentación es compatible con distintos argumentos, aunque no con todos.

El repaso de las diferentes perspectivas ayudará a mostrar lo que hay de sinsentido del problema de PFD: cada perspectiva se ocupa de diferentes asuntos, asuntos que no siempre tienen que ver con la fundamentación normativa. Como se verá, tan sólo la perspectiva epistémica establece una relación fuerte entre democracia y moralidad. Relación que le permite salvar una serie de dificultades en las que -de distinta forma ${ }^{6}$ - incurren las otras perspectivas: ausencia de poder discriminador, esto es, incapacidad para fundamentar la democracia y sólo la democracia; vinculación circunstancial entre democracia y moralidad; inevitable nihilismo en -y por tanto frustración de- el empeño fundamentador; irrealidad de los supuestos empíricos -antropológicos, sobre todo- comprometidos en la argumentación. Dificultades que se traducen en el vaciamiento moral de la idea de democracia. Dificultades que, como se verá en la parte final, no aparecen en la perspectiva en la que se aúnan FE y teoría republicana. En ese sentido, se puede decir que la FE se muestra como la única fundamentación genuina ${ }^{7}$.

\subsection{Tres perspectivas sobre la democracia}

¿Por que, después de todo -se podría preguntar nuestro personaje-, aquello de la democracia no era un simple artilugio para organizar un patio de vecinos un poco grande? Si ese es su sentir, se complacerá al encontrar muchos autores que entienden la democracia como un instrumento, un sistema de toma de decisiones, una técnica que permite traducir muchas voluntades en una, un conjunto de reglas para coordinar preferencias individuales. Pero su gozo no se prolongará mucho. No tardará en comprobar que algunos otros estaban fascinados con una especie de principio democrático que traspasaba con impudicia más de dos mil quinientos años. Los griegos, las repúblicas italianas, las mil formas del parlamentarismo, para ellos -aún si con dispar intensidad- todo era «democracia», sin importar que en unos casos no existiesen representantes o que, cuando existían, «representaran»

6 No hay ortopedia en la precisión: «de forma distinta». No hay inconsistencia entre sostener que las distintas perspectivas se ocupan de distintos asuntos y afirmar que se enfrentan a problemas parecidos. Por ejemplo, dos teorías pueden tener problemas de consistencia, sin que el problema sea el mismo. Cada una lo tiene de distinta -interna- forma. A la vez podemos reconocer que toda teoría satisfactoria -para ciertos problemas explicativos, p.e.debe ser consistente. Del mismo modo, se puede aspirar a identificar los criterios de calificación que debe satisfacer toda genuina fundamentación de la democracia, Cfr. nota siguiente.

${ }^{7}$ Precisamente el que la única genuina fundamentación moral sea la FE permite sostener sin inconsistencia la simultaneidad de inconmensurabilidad entre los enfoques y la superioridad de la FE. Se trata de superioridad relativa a una dimensión específicamente moral que, como se verá, no se encuentra en la FH o en la FI. 
cosas diferentes; que unas veces no hubiera elecciones y otras poco más que enormes escenografías electorales; que otro tanto sucediera con la separación de poderes o con las formas de inserción política (y que entre éstas, por encima de superficiales similitudes, las diferencias fueran abismales, como sucedía con los partidos políticos, verdaderas instituciones proteicas) ${ }^{8}$. A buen seguro, nuestro observador acabaría por concluir que éramos unos metafísicos recalcitrantes, empeñados en una «democracia esencial» más allá de las democracias. Quizá -se diga- no se trate ni de reglas ni de principios: como sucedía con tantas de sus pequeñas mitologías, desde sus dioses hasta sus ritos, no intentaban sino dotar de sentido a biografía pasada a lo que simplemente era historia. También encontraría otros autores dispuestos a alimentar esta opinión, a coincidir en una interpretación social, histórica de la democracia. En suma, concluiría, aquellas gentes no tenían nada claro que era eso de la democracia, confundidos como estaban entre tres ideas: a) un producto histórico; b) un conjunto de reglas (la de mayoría, p.e.) al servicio de resolver algunos problemas domésticos; c) «una metafísica» por encima de sus encarnaciones históricas, un principio difícilmente asible, pero que «se valora por sí mismo».

Consideraciones aparte acerca de nuestra mudabilidad de humores, nuestro estudioso empezaría a pensar que al menos disponía de una explicación para el embrollo de PFD. Cada enfoque estaba hablando de cosas distintas bajo el mismo rótulo $\mathrm{y}$, obviamente, sin acuerdo acerca de qué se está fundamentando el diálogo de sordos resulta inevitable. La solución al PFD dependería del acuerdo acerca de la idea democracia. Se trata de un problema soluble, complicado, pero soluble. Bastaba con precisar el concepto y encarar la tarea fundamentadora. Desafortunadamente, tampoco estaba claro qué se entendía por solución aceptable, cómo abordar la fundamentación. El desacuerdo del concepto se acompañaba del desacuerdo en el procedimiento. Cada una de las perspectivas contemplaba de manera diferente el empeño fundamentador. Y en cierto modo parecía obligado. Pues si la democracia se entiende como simple historia, lo que toca es explicarla o, en todo caso, comprenderla, desde la red de acontecimientos sociales y morales en la que se inserta; si, por contra, la democracia simplemente es un conjunto de reglas para tomar decisiones acerca de la vida colectiva, se justifica como cualquier instrumento desde la finalidad para la cual se construye, y su vida se agota en la medida en la que otra herramienta la sustituya de un modo más eficaz; finalmente, si la democracia es un principio, la cosa es más peliaguda, porque más que justificar, justifica, fundamenta, y la

8 'Sobre tales cambios cfr. Finley (1973); Dunn (1993); Macpherson (1980), Ostrogorski (1993); Manin (1991); Held (1987); Gauchet; Manent; Rosanvallon (1993). Desde una intención afín a la del presente trabajo resulta de especial interés las calas históricas (Grecia, las repúblicas italianas, las revoluciones democráticas, el parlamentarismo y sus fases) y la perspectiva de Manin (1995). 
dificultad radica en determinar que es lo que fundamenta: algunos dirán, con no escaso tino, las buenas decisiones morales.

\section{La democracia como instrumento ${ }^{9}$}

Un conjunto de perspectivas entienden -y fundamentan- la democracia al modo como se da cuenta y se justifica una artefacto: «la estilográfica es una herramienta para escribir»; «el disco compacto es un sistema para almacenar información sonora». En ese aserto hay descripción y razón de existir, teoría y fundamentación. Estas perspectivas acostumbran a utilizar argumentos que guardan similitudes con ciertas defensas -no muy refinadas, todo hay que decirlo- del mercado ${ }^{10}$. Los votantes, como sucede con los consumidores, se enfrentarían a diversas opciones y elegirían según su parecer, según sus preferencias, de modo que, al fin, el estado social (la voluntad general) obtenido sería aquel que satisface al máximo número de individuos. La democracia se presentaría como un modo de reunir las preferencias en una voluntad general. Las preferencias de los individuos se tomarían como dadas ${ }^{11}$, no serían argumento público, no se formarían como resultado o en la actividad política. La parte pública de la democracia se agota en la reunión de las preferencias privadas, preferencias que se forman -por así decir- antes de la democracia y que tienen que ver, según la perspectiva, con la selección de élites, el bienestar colectivo o los intereses en conflicto. La democracia no sería otra cosa que un instrumento imparcial, un conjunto de reglas que permite traducir muchas voluntades en pocas, una función matemática que tiene como dominio las preferencias de los individuos

9 Cfr. J. Mill (1978); J. S. Mill (1956); Schumpeter (1976); Dahl (1956); Singer (1983); Downs (1957); Buchanan, Tullock (1962); Barry (1970); Schmidtz (1990); Wittman (1989).

${ }^{10}$ El mercado neoclásico queda a la vez descrito y justificado como «mecanismo óptimo de asignación de recursos». Sólo es mercado aquello que cae bajo tal caracterización, aquel sistema de asignación que es eficaz (y aquí se puede sustituir «eficaz» por un detallado inventario de condiciones: «información simétrica, producción instantánea, ausencia de economías de escala, de externalidades, etc.»). El mercado queda justificado por su eficiencia y la eficiencia asegurada por definición. Cfr. Ovejero, 1994a, introducción. Sobre los límites de las comparaciones, referidas a las preferencias, entre mercado y democracia cfr. Durilcavy, Margetts (1995).

${ }^{11}$ Como se verá, este «tornar las preferencias como dadas» traza línea de demarcación en las teorías de la democracia, entre una idea según la cual la democracia se agota en el proceso de agregación de las preferencias y otra idea para la que la democracia tiene que ver sobre todo con su formación en pública discusión. Vale la pena advertir que a «tornar las preferencias como dadas» se puede llegar desde: a) la presunción de que la razón es ajena a ellas, que son cuestión de gustos, al modo como la racionalidad es ajena a escoger entre una lata de atún y una de anchoas; b) la presunción de que el individuo es el único tribunal de evaluación y determinación de sus preferencias. Sobre las preferencias en las distintas ideas de democracia cf. Sunstein (1991; 1993); Ferejohn (1993). 
y como rango una voluntad general ${ }^{12}$. La democracia quedaría justificada en la medida en que permite identificar esa voluntad general y realizarla operacionalmente, obtener determinados resultados: la identificación de los más capaces, el máximo de utilidad social o un equilibrio apaciguado de los conflictos. Aquello que se evalúa, justifica y da sentido a ese conjunto de reglas que es la democracia es su potencialidad para acceder a cierto estado final, sus consecuencias, y es -la deseabilidad de- el estado final lo que lleva a construir el instrumento democracia.

Sucede lo mismo con la estilográfica o el disco compacto. Se justifican y construyen porque permiten acceder a una situación o producir un estado de cosas y porque el estado o situación es deseable. El objetivo es el que da sentido a la construcción del instrumento. Interesa una buena audición y por eso hay que quedarse con el disco compacto: es el que mejor se ajusta al propósito y precisamente por eso ha sido creado. El artefacto se justifica (a) en la medida en que el propósito resulta lícito y (b) en la medida en que el artefacto permite conseguirlo óptimamente, en tanto produce eficazmente ciertos resultados o estados del mundo (sonidos, escritura). El primer aspecto es propiamente moral y el segundo, finalmente, empírico: afirma una relación causal entre la herramienta y el estado final de cosas que produce ${ }^{13}$. En ese sentido, en tanto la carga de la prueba moral recae exclusivamente en el propósito, la democracia no tiene más dimensión moral propia que pueda tener una mesa, un artefacto. Desde el punto de vista moral, lo realmente importante, lo discutible o justificado es el estado final. Lo otro, el mecanismo, tan solo se puede discutir empíricamente, acerca de si es cierto

12 Función imposible en condiciones medianamente razonables (dominio universal, transitividad, unanimidad, ausencia de dictadura, independencia de las alternativas irrelevantes) como demostró el teorema de Arrow (1951). Por cierto que se ha tomado esta circunstancia como argumentación en contra de la democracia republicana y en favor de una democracia liberal (o de competencia) que se limita a seleccionar élites, a ejercer la libertad negativa (Riker, 1982; Hardin, 1993). Argumentación que descuida: a) que los teoremas de elección por su propia formulación -no comprometida con qué se elige, con sobre qué recae la elección afectan a la democracia liberal-competitiva; b) que hay razones para pensar que una democracia deliberativa -en la cual antes de votar hay que fundamentar públicamente las preferencias y en donde las preferencias no son sobre interés- reduce razonablemente el conjunto de preferencias y con ello debilita el axioma del dominio universal, uno de los que sostiene el teorema de imposibilidad de Arrow. Cr. (Coleman, Ferejohn, 1986; Christiano, 1993; Miller, 1993).

13 Se podría decir que la idea de democracia cae bajo una descripción funcional al modo como se habla de descripciones funcionales en filosofía de la cognición. La democracia o el disco son simples realizaciones de ciertos procesos causales en los que ciertos inputs (preferencias, sistemas de lectura) causan ciertos outputs (voluntad general, sonidos). Las propiedades funcionales pueden «instanciarse» materialmente de modo diverso. Lo importante es que caben diversas -al menos una- realizaciones de una misma descripción funcional. En el caso de la democracia no resultarían inimaginables diversos mecanismos de realización; un supuesto lector mental de preferencias, votación informática, etc. Mecanismos que de diferente forma causan -realizan- el proceso de obtención de las preferencias. 
o no que permite obtener ciertos resultados. Precisamente por eso es de desear que el instrumento sea el mejor. Si no es así, dejará de estar justificado: habida cuenta de que lo que actúa como cimiento fundamentador es la buena audición o la máxima utilidad, que son los valores no discutidos (aunque discutibles), resulta razonable exigir que se escoja el mejor instrumento para su realización. El disco de vinilo, romanticismos aparte, deja de estar justificado cuando se dispone del disco compacto. De la misma manera, la democracia, como el disco, es superable e inevitablemente está llamado a ser superada. El artilugio, porque es instrumento, sólo se justifica si es el mejor para producir lo que produce.

\subsection{Los rasgos de la justificación instrumental}

En general, la justificación de Y (la democracia, el disco compacto) desde X (la resolución de los conflictos, la audición) exige mostrar: a) que existe una vinculación -causalde $\mathrm{Y}$ con $\mathrm{X}^{14}$; b) que esa vinculación es óptima respecto al propósito que da sentido a $\mathrm{Y}$; c) que $\mathrm{X}$ es bueno o interesante en algún sentido. La fundamentación utilitarista es un buen ejemplo de estas justificaciones. En su caso, las tesis fundamentadoras serían: a) la democracia permite realizar $^{15}$ el bienestar; lo hace mejor que cualquier otro marco institucional ${ }^{16}$; c) el bienestar es un asidero último no discutible.

14 Como se verá, esta premisa es la que reclama una teoría de la democracia. Teoría que, en principio (Lewis, 1983), siempre se puede describir funcionalmente: un proceso causal siempre admite una descripción funcional, la descripción de como a través de un proceso ciertos inputs dan lugar a ciertos outputs. Es una caracterización funcional los términos adquieren su significado por el rol causal que se le adscribe en la teoría a la entidad a que se refiere; así, p.e., un alimento es una sustancia que cuando es digerida produce/causa la nutrición de los organismos. El rol causal del concepto alimento admite diversos ocupantes. Cuando se trata de un artefacto la funcionalidad remite a un propósito para el que se crea. En el caso que nos ocupa, como se dijo en la nota anterior, diversos ocupantes (lector mental, etc.) instancian (realizan) la obtención de las preferencias o -directamentepropician la maximización.

15 O determinar las preferencias, lo que los individuos quieren satisfacer. Obviamente las dos ideas («determinación de preferencias» $\mathrm{y}$ «satisfacción») no son equivalentes en la fundamentación de la democracia porque: a) la determinación de las preferencias puede no traducirse en la satisfacción; b) la satisfacción (bienestarismo objetivo) puede prescindir de la determinación por vía democrática; e) la maximización del bienestar, aún si compatible con la democracia, puede no estar relacionada directamente con las preferencias entendidas como expresión de los deseos: por ejemplo, las preferencia podrían recaer sobre las élites políticas y éstas estarían obligadas a averiguar -y satisfacer- los deseos; en este caso las preferencias no tienen que ver directamente con la satisfacción de los deseos, se limitan a actuar sobre ciertos actores -las élites- que están obligados a escrutarlas y satisfacerlas. Por lo demás, tampoco ha de confundirse (d) la satisfacción de preferenciar con el sentimiento -o creencia- de satisfacción.

16 Este requisito -tremendamente fuerte- viene dado por el carácter consecuencialista del utilitarismo. Mientras que las éticas deontológicas simplemente se limitan a tomar la forma negativa («no hacer $\mathrm{x}$ », «no es deseable la institución w»), las consecuencialistas toman la forma de: "hágase Y», donde "Y» se corresponde con la única estrategia óptima. Las primeras son compatibles con muchas acciones $(\mathrm{y}, \mathrm{z}, \ldots)$ y en ese sentido son poco exigentes; por contra, las segundas exigen mucho, sólo son compatibles con una acción, con el óptimo, con Y. Es sabido que el utilitarismo, que exige actuar según el óptimo, requiere héroes sin tregua, individuos poco «utilitaristas» (en el sentido del homo oeconomicus). Sobre estos aspectos del consecuencialismo cfr. los trabajos de Railton, Parfit y Scheffler incluidos en Scheffler (1988). Sobre el «sentido común» de tales exigencias morales, de reclamar que se actúe según el máximo bienestar colectivo cfr. Kagan (1989). 
[De lo dicho se sigue que la crítica -interna, compartiendo enfoque- a una fundamentación puede: a) mostrar que no existe tal vinculación; b) mostrar que existen instituciones que mantienen una conexión más discutible, menos frágil, con el valor fundante ${ }^{17}$; c) discutir el presunto interés del objetivo último. Las dos primeras críticas son internas en sentido estricto, comparten método y comparten criterio de valoración. La última, aún si de acuerdo en la perspectiva instrumental, critica el objetivo, el valor. La realización de una sola de las tareas es condición suficiente para desmontar el empeño fundamentador. En el caso del utilitarismo, para seguir con el ejemplo, se podría discutir: a) si la utilidad es un buen baremo; b) si la democracia garantiza la maximización del bienestar; c) si no existen sistemas de organización política que garanticen de un modo mejor el bienestar ${ }^{18}$. Todas esas críticas son posibles y todas se han ejercitado. Se ha discutido que el bienestar sea un correcto criterio último para evaluar las acciones y los estados sociales ${ }^{19}$; que la democracia -entendida como un conjunto de reglas de agregación- permita realmente pasar de un modo inequívoco desde las preferencias de los individuos a la voluntad general $^{20}$; y que no existan procedimientos mejores para realizar el bienestar que la agregación democrática $\left.{ }^{21}\right]$.

${ }^{17}$ Por lo dicho en la nota anterior esta crítica sólo valdría para las fundamentaciones consecuencialistas, no para las deontológicas. Para éstas basta con la existencia de una conexión razonable -no la mejor- entre el valor fundante y aquello que funda.

${ }^{18}$ Es importante destacar el requisito de que la vinculación sea óptima. Lo que realmente fundamenta -el valor no discutido- es $\mathrm{Y}$. X es simplemente un instrumento para la realización de Y. Y siempre resulta razonable cuando se persigue un objetivo escoger el mejor medio para su consecución.

${ }^{19}$ Las críticas por esta vía han sido diversas: el objetivo de maximización del bienestar es compatible con situaciones de desigualdad; se ignoran consideraciones relativas a dimensiones importantes que no quedan recogidas bajo la utilidad (autorrealización, respeto, amor); se muestra indiferente al cómo, a la vía por la cual, se obtiene el bienestar; etc. Cfr. Sen, Williams (1982); Elster, Roemer (1991); Anderson (1993).

${ }^{20}$ La teoría de la elección social muestra de muchas maneras -desde el teorema de Arrow- la imposibilidad de una función que tomando como argumento las preferencias individuales se traduzca sin problemas -de consistencia, de pluralidad- en una única preferencia colectiva. Para un repaso general de tales resultados cfr. Mueller (1989); con una mayor sensibilidad hacia los problemas que aquí nos ocupan cfr. Wriglestorth (1985).

${ }^{21} \mathrm{Al}$ cabo, un modo de salvar los problemas del teorema de Arrow es relajando la hipótesis democrática, esto es, asumiendo que las preferencias de un individuo, de un dictador, son las preferencias sociales. Por otra parte, si lo que importa es el bienestar, antes que la libertad para elegirlo (y no hay que olvidar que nos manejamos con teorías consecuencialistas para las que la libertad por sí misma no es relevante) o si no se asume el supuesto de suyo arriesgado de que los individuos saben -sin más- qué es lo mejor para ellos, podría muy bien pensarse en que una dictadura provista de una especie de lector mental o hermeneuta universal es lo que mejor se acomoda a la justificación utilitarista. Buena parte de los argumentos que discuten las preferencias (o bienestarismo) «subjetivas», «privadas» implícitamente apuntan en esta dirección, cfr. Sunstein (1991; 1993); Ferejohn (1993). En el mismo sentido muchos de los argumentos que repiensan la idea de representación y que recuerdan que la voluntad general se manifiesta de formas ajenas a las elecciones cfr. Paterman (1970); Manin (1987). 
Pero no interesa ahora la patología, sólo la anatomía, la estructura de la justificación; en particular, dos aspectos que permiten reconocer la peculiaridad de la fundamentación instrumental. Primero, la fundamentación es interna al plano axiológico: arranca desde premisas morales más básicas, anteriores sólo en sentido lógico, no histórico o epistémico. Cuando un utilitarista trata de justificar la libertad de prensa no escapa del plano axiológico ${ }^{22}$, no apela a circunstancias históricas, a condiciones sociales o a principios acerca de procedimientos de argumentación, a condiciones (epistémicas) de formación de juicios morales. Diría, por ejemplo, que la libertad de prensa permite conocer mejor los deseos de los individuos y disponer para su satisfacción mecanismos institucionales mejor engrasados. Vincula unas acciones o valores con un valor o criterio más fundamental, no discutible, como el bienestar ${ }^{23}$ (aunque si la fundamentación se quiere completa -y un poco paradójica- dará razones en favor de ese valor, del bienestar). Trata de mostrar que la acción o el valor está directamente relacionado con -maximiza- la utilidad. En ese respecto la fundamentación se asemeja a las explicaciones de la ciencia. Cuando predecimos un eclipse con las leyes de la mecánica clásica no «salimos» del plano empírico: pasamos de las premisas a las conclusiones en una inferencia estricta, sin que medien juicios acerca de las condiciones de conocimiento o sobre las reglas de funcionamiento de las comunidades científicas. Del mismo modo, tampoco la fundamentación instrumental da cuenta de las acciones morales desde premisas históricas, desde la sociología o la biografía, ni desde las condiciones en que se construyen los juicios morales. Es en ese sentido en el que se habla aquí de fundamentación interna.

El segundo extremo tiene que ver con cierta ambigüedad inevitable de la primera premisa, con aquella que establece una vinculación entre el valor que justifica (X) y lo que se justifica (Y), entre la utilidad y la democracia, por ejemplo. La ambigüedad se presenta sobre todo cuando nos enfrentamos

22 Aunque obviamente siempre hay supuestos empíricos como en cualquier argumentación moral, supuestos presentes en la primera premisa. En ella se esconde una afirmación acerca de una secuencia causal entre una acción (o institución) y unas consecuencias, afirmación que puede ser compatible o no con las observaciones.

23 Para lo cual se necesita una teoría. Precisamente radica aquí una de las dificultades mayores de las estrategias consecuencialistas: la ausencia de instrumentos poderosos, de teorías, que nos permitan operacionalizar doctrinas tan -presuntamente- operacionales como el utilitarismo. Lo cierto es que a la vista de la incapacidad para «echar las cuentas» (entre otras razones por los problemas de la unidad de medida: la utilidad, cfr. nota 5), una teoría cuyo argumento fundamental es que «hay que echar las cuentas y dejarse de historias» queda en un triste papel. Al final el utilitarismo también acaba pasteleando para acomodarse a las intuiciones morales. Si realmente fuera una teoría poderosa, con potencia de cálculo, las predicciones -acerca de que acción es la que realmente maximiza la utilidad- tendrían que ir por delante y aún en contra de las intuiciones, podrían, por ejemplo, promover un sorteo para matar unos pocos individuos y transplantar sus órganos a muchos otros. Y son pocos -Singer (1979) sería una excepción- los utilitaristas dispuestos a discutir «lo natural». 
a la justificación de instituciones, en tanto estas requieren alguna caracterización que permita reconocer a la institución. En principio, la caracterización de lo que se justifica debe ser independiente de la perspectiva justificatoria ${ }^{24}$. No se consideraría con muchos vuelos una justificación de « $\mathrm{X}$ » en nombre de «y» que arrancara estipulando que «x es y». Por ejemplo, la afirmación «la democracia permite realizar el bienestar» exige, si no se quiere vacía, una idea de democracia que no incluya inmediatamente la idea de bienestar. Necesitamos saber «qué es la democracia», necesitamos una teoría de la democracia que nos permita reconocer la democracia, al modo como la teoría atómica -que caracteriza al átomo por una serie de propiedades: cargo, masa, spin, etc.- nos permite reconocer un átomo. Desafortunadamente, la propia caracterización instrumental de la democracia impone una referencia a los objetivos, que es, de facto, a la vez que una teoría de la democracia, una justificación del por qué de la democracia.

Para justificar la democracia, para ver si satisface el criterio moral, necesitamos saber qué es una democracia. Para saber qué es una democracia necesitamos, a su vez, una teoría de la democracia, una estipulación de qué es la democracia. Pero es el caso que, en virtud de la caracterización instrumental, la estipulación de qué sea la democracia supone, de forma más o menos implícita, una apelación a fines («la democracia es aquello que permite conseguir $\mathrm{x} »)$, apelación que cancela el empeño fundamentador ${ }^{25}$. En buen hacer la premisa «la democracia permite $\mathrm{x}$ » debería ser un simple juicio

${ }^{24}$ Por ejemplo, cuando se intenta justificar (o criticar) la eutanasia, una cosa es el principio (el derecho al propio cuerpo, la vida como valor esencial, p.e. y otra aquello que se fundamenta, sobre lo que no parece haber desacuerdo al identificarlo. Pero esto, que vale -como se dijo en la nota 4- para sucesos poco complejos, reconocibles preteóricamente por así decir, resulta más complicado en el caso de instituciones o procesos.

25 El utilitarismo lo muestra bien. El criterio utilitarista de justificación es bien conocido, aunque ha adoptado diversas fórmulas, según lo que se maximice: la utilidad agregada, el bienestar medio o per cápita, el producto de los bienestares individuales. La justificación de la democracia se sostiene en dos premisas: una primera, nuclear, que vincula las preferencias con la utilidad, que describe la utilidad como la satisfacción de las preferencias; una segunda que afirma que «la democracia es la expresión de las preferencias». De modo que si la utilidad se expresa a través de las preferencias y la democracia actúa como el indicador de las preferencias, es obligado concluir que «la democracia es la expresión del bienestar». Por definición (instrumental), la democracia queda justificada.

En todo caso, una discusión pormenorizada de la fundamentación utilitarista requeriría una caracterización anterior más morosa. En tal caso, seguramente, quedaría claro que la propia falsa precisión de la utilidad -y la circularidad que esa impresión alimenta- afecta al núcleo mismo de la justificación. No se insistirá lo bastante en la ambigüedad de «la utilidad». El uso que aquí se hace, poco refinado, se ajusta más al común entre filósofos políticos pero ni aún entre economistas, la más precisa idea de función de utilidad resulta clara; unas veces se piensa como una especie de propiedad substantiva asociada a los bienes, que proporcionan «utilidad», a sus consumidores, y en otras como un simple orden de preferencias. En el primer caso, las complicaciones vienen por el esencialismo y las preferencias se relacionan con la utilidad como las virtudes opiáceas con el opio; en el segundo, las complicaciones proceden de que el orden no anda referido a una propiedad «estable» como pueda ser el peso, la longitud o la temperatura, sino a lo que cada individuo en cada instante ordena. (Repárese en lo que sucede si se toma otra idea de bienestar, de utilidad, lo que se ha llamado «bienestarismo objetivo», que separa el bienestar de la satisfacción de las preferencias manifestadas inmediatamente por los individuos porque duda que éstas tengan que ver con aquél. En ese caso, el conjunto de la argumentación queda reconstruida. No es causal que ese bienestarismo objetivo acompañe con frecuencia a otra idea de democracia, republicana, según la cual, «la democracia es la formación de las preferencias», a través del diálogo público que lleva a los individuos a reconocer sus «reales preferencias»). 
empírico que nos informa de que la democracia, además de una serie de rasgos que la identifican, se da la circunstancia de que «permite x». No sucede de este modo en la FI. En ésta, dicha premisa es, además de una pieza de la argumentación moral, una apretada teoría de la democracia ${ }^{26}$-y en ese sentido una definición- que afirma que «la democracia es el sistema que permite $\mathrm{x}$ (maximizar la utilidad, seleccionar élites, etc.)». Teoría que caracteriza funcionalmente a la democracia como causante de ciertos resultados, precisamente los mismos que sirven para justificarla.

\subsection{Los límites de la fundamentación instrumental}

Los dos aspectos mencionados, conjuntamente, debilitan el proyecto fundamentador. La democracia se muestra inevitable y trivialmente justificada: de una parte no se sale del plano moral y de otra, en virtud de su caracterización instrumental, la democracia viene descrita (funcionalmente) desde los fines ${ }^{27}$. En ese sentido, la democracia se muestra vacuamente moral, resulta moral por definición. Una vez establecida estipulativamente la calidad moral de la democracia -no otra cosa es una definición: una estipulación- la empresa misma de justificación moral se revela un sinsentido. La

${ }^{26}$ En el sentido señalado en la nota 2, esto es, una teoría como una definición que incorpora un conjunto de conceptos y de relaciones entre conceptos (de leyes). Como allí se dijo, una teoría no puede no encontrar sistemas reales a los que referirse. Sin embargo, teorías sin referentes pueden cumplir una función normativa. Así por ejemplo la teoría del socialismo de mercado es una teoría sin modelos, aunque nosotros podríamos estar interesados en construir sistemas reales que fueran modelos de dicha teoría. Lo mismo se podría decir de la democracia republicana.

27 En principio, separar la fundamentación instrumental (la democracia permite la maximización de cierto valor $\mathrm{x}$ ) de la caracterización funcional (la democracia es un sistema para $\mathrm{x}$ ) debilitaría en parte las anteriores objeciones. Se trataría de explorar la posibilidad de mantener la primera sin comprometerse con la segunda, de tal modo que la teoría de la democracia -siempre necesaria para identificarla- no adoptará en forma más o menos velada un tono funcional. De todos modos: a) hay razones para pensar (Lewis, 1983) que, como se apuntó en las notas 13 y 14, la premisa que relaciona la democracia como productora -como causa de ciertos resultados es traducible en una caracterización funcional, y aún más en el caso de un artefacto construido (algo que es/sirve para x), como sucede de un modo u otro con las instituciones; b) si la teoría de la democracia pudiera prescindir de una descripción en forma de consecuencia, necesitaríamos alguna otra premisa adicional que nos permitiera relacionar a la -teoría de- democracia con el valor justificatorio, con lo que el problema reaparecería. 
consecuencia es el carácter escasamente moral de la democracia en la $\mathrm{FI}^{28}$. Circunstancia que se muestra de diversos modos:

1. La FI deja la moral fuera de la democracia. Se ampara, como se ha visto, en un par de juicios fácticos, que relacionan óptimamente la democracia con determinado estado de cosas, y uno moral que reconoce como deseable ese estado de cosas. La democracia sólo aparece en la primera parte. Al igual que un puente o cualquier otro instrumento tecnológico, sirve a un propósito moral, pero no es propósito moral o lugar de la reflexión moral. Un arma o un medicamento, son productos técnicos que se construyen porque se juzga deseable el estado final que contribuyen a alcanzar. Si hay que discutir moralmente algo es el estado final, los objetivos. Pero esa es ya una discusión que prescinde de la democracia, una discusión sobre valores como cualquier otra. La democracia no es el argumento de la obra moral.

2. La vinculación entre democracia y moral es circunstancial. La vinculación no es fuerte en ningún sentido. La segunda premisa, que afirma una relación óptima entre la democracia y un cierto estado de cosas, reconoce implícitamente la posibilidad de que otro sistema pueda satisfacer mejor al mismo objetivo: la democracia está justificada mientras sea el mejor medio y, por ende, no es condición necesaria de ningún estado de cosas deseable. Dicho de otro modo, la democracia es superable.

La débil vinculación entre democracia y moralidad se deja ver también desde otra perspectiva, desde la incapacidad de la FI para rescatar una sólida intuición moral que asocia inseparablemente democracia a progreso moral. Pues es el caso que una vez se asume que la democracia puede ser superada cabe pensar en separar la democracia de la idea de progreso moral. Cierto es que la intuición es siempre un endeble asidero -aunque, con reservas, es de los pocos disponibles en los negocios morales ${ }^{29}$ - y no conviene fiarlo todo en ella; sin embargo, en el presente caso sirve como índice de

28 Desde otro punto de vista se podría decir que hay una tensión entre: a) externalizar la fundamentación moral, en cuyo caso la primera premisa (la democracia permite $\mathrm{x}$ ) es un juicio empírico y toda la enjundia moral queda en una premisa ( $\mathrm{x}$ es deseable) que no compromete a la democracia; b) internalizar la fundamentación, en cuyo caso la primera premisa se convierte en una estipulación de qué sea la democracia (la democracia es el sistema que permite $\mathrm{x}$ ) $\mathrm{y}$, en tanto la democracia es sinónima de $\mathrm{x}$, de lo que se trata es de discutir sobre $\mathrm{x}$. En uno y otro caso, hay una teoría de la democracia. En la primera opción implícitamente, a través de un conocimiento básico que sirve de soporte a una tecnología (la argumentación es la propia de las inferencias tecnológicas: x produce y; y es deseable; por tanto: constrúyase $\mathrm{x}$ ). Pero, en ese caso, resulta difícil rescatar la intuición que se oculta detrás de juicios como «la democracia es moral». En la segunda opción la presencia de la teoría es más inmediata y deriva de la caracterización funcional aludida en las notas 13 y 14.

29 Sin embargo, la frecuente comparación entre intuiciones morales versus teorías normativas y observaciones versus teorías empíricas tiene un alcance limitado. Los abundantes estudios empíricos sobre la justicia confirman razonables dudas acerca de dicho alcance: a)no hay -ni siquiera en principio- acuerdo general acerca de las intuiciones compartidas, mientras que las observaciones -con todas las reservas recordadas por más de cien años de filosofía de la ciencia- siguen teniendo su función de tribunal último; b) las intuiciones -mejor, los juicios que sostienen a las intuiciones- no se muestran consistentes, mientras que las observaciones -sus enunciados- sí: no puede haber sistemas reales -modelos- inconsistentes; e) la propia exploración empírica de los criterios normativos -en su ámbito explicativo (Elster, 1995)- muestra que los propios determinantes subjetivos de muchas intuiciones (egoísmo, p.e.) están en desacuerdo con muchas intuiciones, mientras que nada parecido cabe imaginar en el otro terreno. 
algo poco complicado pero importante: sencillamente no sabríamos qué significa separar democracia de progreso moral. La FI, que reconoce superable la democracia, se ve en la obligación de hacer inteligible esa incapacidad y no parece estar en condiciones de hacerlo ${ }^{30}$.

3. Para la FI la democracia aparece como un conjunto de reglas que permiten obtener la voluntad general a partir de voluntades individuales. En el límite la democracia viene a ser una especie de termómetro que traduce neutralmente los estados de opinión en un valor reconocible, la voluntad general. La pertinencia de esa idea ${ }^{31}$ no parece discutible cuando pensamos en gustos últimos $^{32}$ o intereses muy acotados ${ }^{33}$. No todas las elecciones son (igualmente) morales. La falacia que asimila elección a elección moral descuida que no es lo mismo elegir un programa político que elegir un postre (o que elegir una conjetura explicativa). Sin embargo, desde la perspectiva de la FI no hay diferencia entre el postre y el cómo vivir. Las elecciones no requieren razones, las preferencias sólo remiten a ellas mismas, son palabra última. Hacer de toda elección cuestión de gusto, acaba por dejar a la democracia

30 Siempre cabe la réplica de que el significado «de la superación de la democracia» se aclarará o disolverá cuando dispongamos de otro instrumento mejor, al modo como sucede en la ciencia donde ignoramos hoy las preguntas que las nuevas teorías o escenarios nos llevarán a realizar y las viejas preguntas se contestan o dejan de ser significativas a la luz de las nuevas teorías. Pero la comparación más adecuada no es esa, sino -dicho clásicamente- con ciertas -no todas- categorías kantianas, ciertas condiciones a priori en las que se funda la posibilidad de la experiencia; o, en versión más moderna, y menos comprometida metafísicamente, con el conjunto de convenciones desde las que construimos el conocimiento. Pensemos por ejemplo, en lo extraña que resulta la idea de superar el principio de causalidad (no confundir con la explicación causal). Desde luego, no podemos imaginar un modo de refutarlo. Sencillamente, nos permite entender el mundo y es desde él desde donde producimos juicios empíricos. Podemos reconocer que en ocasiones erramos al identificar una causa, pero eso no quiere decir que no exista una causa. Más abajo, al referirnos a la fundamentación epistémica, se ahondará en la comparación.

31 Otra cosa es que no existan problemas técnicos derivados de la imposibilidad de obtener una función de elección social, problemas que invitan a pensar que la teoría de la elección colectiva se debería llamar la ciencia del pesimismo democrático. Cfr. nota 12.

32 Obviamente para productos con algún rasgo de bien público, sin posibilidad de consumo exclusivo, que es lo propio de buena parte de los asuntos políticos. No hay problema en que uno coma paella y otro cocido; pero otra cosa es la elección de un emblema o de los colores de la bandera. De todos modos, cfr. notas 70 y 71 .

${ }^{33}$ Que no admiten transacciones (se trata de A o B, sin posibilidades intermedias), que no requiere razones y con soluciones alternativas costosas, con costos fijos (sin posibilidad de un tiempo A y otro B), como puedan ser la apertura hacia la izquierda o la derecha de la puerta de un ascensor en una escalera con vecinos diestros y zurdos. Cfr. notas 70 y 71 . 
sin defensas, sin posibilidad de ser justificada. Si todo es igual, todo da lo mismo y no hay razones para escoger nada. No hay diferencia moral entre dedicar los recursos públicos -o la vida de uno: en este nivel las dos elecciones se equiparan- al culturismo o a organizaciones humanitarias.

Aún más, la propia idea de mayorías o minorías, desprovista de vínculos con la argumentación, pierde todo sentido. Si no hay ninguna razón para A antes que para B, la idea de que en algún sentido la mayoría tenga razón pierde cualquier significado ${ }^{34}$, habida cuenta de que no hay nada parecido a la razón en ningún sitio $^{35}$. No es sólo que la democracia deje de ser el argumento de la obra moral, es que tampoco es el escenario, porque lo que se representa no parece tener que ver con la moral.

Las manifestaciones de esta circunstancia se dejan ver de distintos modos. Por una parte, la democracia acaba por desembocar en un pluralismo relativista desprovisto de todo vigor moral, incapaz de aceptar razones en favor de las diferentes ideas o proyectos de vida. La propia libertad se torna

${ }^{34}$ Se han aducido muchas razones en favor de la regla de la mayoría: que economiza la violencia, en tanto traduce la fuerza mayor; que resulta más eficaz, en tanto resulta fácilmente asumida; que tiene bajos costos de negociación; etc. La más sólida es la que se relaciona con el Teorema de May, teorema que demuestra que la regla de mayoría se infiere de un conjunto de principios axiomas bastante razonable: inambigüedad, anonimidad, neutralidad, respuesta positiva. Demostración que se interpreta a veces (Ackerman, 1980: 277-ss) como una muestra concluyente de que dicha regla traduce una elemental idea de igualdad liberal: no tratar a nadie como incondicionalmente superior; la opinión de cada uno es tan buena como la de otro. Sin embargo, esta argumentación no está exenta de dificultades. En primer lugar, la igualdad de poder político abarca bastante más que la regla de la mayoría: las loterías -que as eguran igualdad de probabilidad de acceso al poder- o, incluso, las dictaduras, donde todos tienen el mismo poder, es decir, ninguno. Por otra parte, aún aceptando la mencionada interpretación del teorema de May, las cosas no son sencillas: si los individuos son igualmente arbitrarios -esto es, si no se introduce alguna reserva a la fundamentación de los juicios- tener o no en cuenta la opinión de la mayoría no es igualmente respetuoso, sino igualmente irrelevante. Finalmente, hay que ser cauto con equiparar una sociedad máximamente libre con una sociedad máximamente democrática entendida como una sociedad que "Somete todo a decisiones colectivas y otorga a todos sus miembros un igual poder en lo que se decide» (una sociedad que satisficiera tales requisitos estaría en condiciones de decidir como me tengo que peinar yo difícilmente se la podría calificar como «sociedad libre»). Dicho de otro modo: el requisito de que los ciudadanos tengan el máximo poder decisional no equivale que sean máximamente libres (Van Parijs: 1995:8).

Lo anterior no quita para reconocer buen sentido en la regla de la mayoría. Pero eso exige: a) evitar confundir la igualdad política con la igualdad de peso político (Dworkin, 1990); b) relacionar la mayoría con los procesos de persuasión y argumentación (cfr. la evolución de Nino: 1989); c) repensar la idea de igualdad política desvinculándola de la idea liberal de que todas las opiniones valen lo mismo, idea que en rigor se revela poco respetuosa con las distintas ideas (el respeto se asegura desde la disposición a tomarse las ideas en serio, esto es, a discutirlas; y discutir una idea supone reconocer la posibilidad de que valga menos -o más que las demás, en ningún caso presumir -esto es, afirmar por derecho, por principio- que todo vale lo mismo, asunto que es materia de valoración nacional (Beitz, 1989)).

35 Eso no impide que se pueda justificar la regla de mayoría por las otras razones recogidas en la nota anterior. Cfr. Offe (1992: cap. 4). 
en el simple instrumento de una elección sinsentido -no en un valor defendible por sí mismo- y la imparcialidad en simple indiferencia moral. Por otra, al hacer de la democracia una mera regla de agregación de preferencias y de las preferencias una cuestión de «gusto» privado, se traza una aguda demarcación entre un escenario privado en donde «la opción» carece de razones, y de toda justificación, y un escenario público en donde ya sólo cabe la confrontación y el equilibrio o agregación de «los gustos». De manera que la reflexión moral queda expulsada de todas partes. Sin criterios de valoración, se concluye que cualquier preferencia vale lo mismo que cualquier otra, lo que equivale a decir que ninguna vale nada y, al fin, a recalar en el nihilismo. Así las cosas, la idea misma de fundamentación moral pierde todo sentido. La paradoja liberal parece entonces inevitable: si todo vale lo mismo, si nada es mejor que otra cosa, si no hay razón para elegir, resulta difícil justificar la propia libertad (de elección) ${ }^{36}$.

En suma, la FI: a) subordina la fundamentación al valor que sirve para fundamentar y, con ello, desprovee a la democracia de contenido moral; b) no establece una vinculación fuerte, necesaria, entre la democracia y la moralidad; c) reconoce la pertinencia de la pluralidad pero al precio de asumir un relativismo incondicional que hace imposible el discurso moral, un nihilismo que, por definición, hace naufragar cualquier fundamentación. (Hay una dificultad adicional: d) el irrealismo empírico ${ }^{37}$ de los presupuestos implícitos en la idea de «individuos que eligen según sus preferencias». Dificultad que se expone a continuación, en tanto constituye el punto de partida de la FH).

\section{La democracia como historia ${ }^{38}$}

Si nuestro conveniente científico interplanetario, sin abandonar su aprecio por las cosas tangibles y su descreimiento por la especulación, antes que un pragmático optimizador de imprecisos objetivos es un pulcro historicista,

\footnotetext{
${ }^{36}$ Para una formulación más precisa cfr. más abajo nota 51.
}

37 Toda teoría normativa tiene supuestos empíricos más o menos explícitos. Por ejemplo, la utopía del mercado neoclásico, supone -no sólo una irreal idea acerca de las condiciones de producción sino también- un irreal modelo antropológico a la vista de las capacidades de computación -comparación, ordenación, rapidez de actuaciónde la especie humana; el socialismo tradicional ha manejado unas condiciones de abundancia y/o de sanidad no menos irreales. El primer requisito para que sea considerada es que tales supuestos no sean falsos, que resulten compatibles con el conocimiento disponible. Sobre la irrealidad de los supuestos de comportamiento cfr. Ovejero (1994b: 336-ss) y para un repaso sencillo de la literatura reciente, referida en general a los supuestos de racionalidad: Palmarini (1995).

38 Cfr. Sandel (1982); Walzer (1981; 1990); Rorty (1983); MacIntyre (1983) Taylor (1995), Unger (1987). Importa destacar que estos autores comparten -en diverso grado- una buena disposición hacia el liberalismo y la democracia. No al liberalismo como filosofía política, sino a un conjunto de instituciones -la democracia entre ellasque intentan «recuperar» o «reinterpretar» sobre cimientos nuevos. Para una presentación -socrática- sistemática y en réplica a los críticos liberales cfr. Bell (1993). Con particular interés en las estrategias de argumentación y en ese sentido más cercano a los aspectos de fundamentación aquí considerados, Ingran (1995). 
en el buen sentido, en él de Ranke, un amigo de los datos y de la reconstrucción totalizadora de los modos de vida de las gentes, muy bien puede comulgar con una visión comunitaria de la democracia, para la cual, la idea de fundamentación, en su sentido convencional, tiene escaso sentido. Al fin, razonará, nadie se preocupa por los fundamentos morales del Paleolítico o del Renacimiento, simples productos históricos, y tampoco nadie debería hacerlo con la democracia o el mercado. Tan solo cabe entenderlos, explicarlos y, a lo sumo, ya en la vecindad del terreno moral, comprenderlos. Los filósofos políticos que exprimen la constitución norteamericana o los Federalists Papers y sus principios tratando de mostrar su calidad de guías o procedimientos para resolver problemas contemporáneos ${ }^{39}$ deberían, antes que otra cosa, atender a la historia menuda, a los conflictos entre sus gestores o a los escenarios morales en los que se desenvolvían. Esa es la única manera lícita y provechosa de encarar aquellos asuntos. Lo otro es simple filosofía de la historia: tratar de cuadrar en el orden de la secuencia histórica las confusiones de la moral, querer confundir la lógica con la historia.

La democracia es, si defendible, modo de vida, estar compartido. Y la vida no se explica, sino que se cuenta a la vez que se entiende. La correcta tarea es la propia de un narrador o, en todo caso, de un antropólogo que cuenta historias completas sin desatender capilar social alguno. Las preguntas y las justificaciones vienen después, cuando ya no hay remedio, cuando la red se rompe y quiméricamente se quiere reconstruir desde un simple cabo. El intento fundacionista es, él mismo, testimonio de una realidad moral fragmentada, de una sociedad que ha perdido sus argamasa moral compartida. Precisamente porque han desaparecido los nortes que imprimían dirección y sentido a la vida de las gentes, es por lo que surge el insensato problema de «por qué el norte». Sólo cuando las vidas se vacían de sentido aparece el problema del sentido. El PFD resulta interesante no como programa de investigación, embarcado como está en un falso problema, sino como testimonio de otro asunto, el verdaderamente importante, la presencia de una sociedad atomizada, sin alma colectiva. La aspiración trascendental, ese punto de vista más allá de los puntos de vista, la instancia metamoral, es una quimera que revela con su simple existir la ausencia de

39 Es lo que en buena medida sucede con el magnífico esfuerzo de Ackerman (1993) por proporcionar avales históricos a su sensato republicanismo, a su república capaz de cimentarse en ciudadanos activos -sólo- en ciertos periodos revolucionarios, pero no supererogatorios. Esfuerzo que, todo hay que decirlo, en no pocas ocasiones recuerda los titánicos esfuerzos de muchos marxistas durante muchos años por acomodar la filología y las buenas razones. Cfr. en la misma línea buena parte de los trabajos incluidos en Elster, Slagstad (1988). 
asideros morales: la necesidad de encontrar -para decirlo a la antigua usanza- sentido a la vida, cosa que sólo sucede cuando la vida no tiene sentido.

Desde esta perspectiva, el proyecto anterior y, en general, el PFD, reposa en un cúmulo de errores. Hay: a) errores de principio: la democracia es historia y la historia se explica, se cuenta o se recrea, pero no se fundamenta ni se demuestra; b) errores de procedimiento: si hay que abordar la democracia con mirada moral no es para evaluarla, para echarle cuentas desde unos valores o propósitos últimos, más allá de la historia, sino para comprenderla, para hacerla inteligible en su interna necesidad, desde unas redes morales, sociales o lingüísticas en las que se inserta como una pieza más; c) errores metafísicos: no hay individuos descarnados, anteriores a sus deseos e intereses. Los individuos son nudos de voluntades y propósitos tramados por sus biografías $^{40}$, no eligen sus preferencias, son sus preferencias y éstas,

${ }^{40}$ Hay aquí un error importante que se deja ver en ciertas críticas comunitaristas a la Teoría de la Justicia de Ralws. El conjunto de esa argumentación ignora la naturaleza de los instrumentos (la teoría de la elección racional) y aún el propósito de Ralws. Pero hay algo más. La inexistencia fáctica, o mejor, la falta de trazos históricos, del individuo que está tras el velo de la ignorancia se toma como un argumento contra la fundamentación de principios de justicia, "por tratarse de un individuo irreal, de un supuesto imposible». Pero un individuo sin atributos no es un individuo con falsos atributos. Sin embargo, una argumentación que sin trampas llevara desde premisas no valorativas hasta un valor -esto es, si salvase la falacia naturalista- se mostraría extraordinariamente robusta (sería el equivalente a la obtención en inteligencia artificial de propiedades semánticas desde reglas sintácticas). Cualquier teoría moral que arrancase sin restricciones éticas (ese ha sido siempre el propósito del utilitarismo) obtendrá una fundamentación independiente de compromisos específicos y por tanto tendría un alcance incondicionado, se mostraría válida para cualquier escenario, al modo como una teoría empírica que no hace referencia a circunstancias locales vale para todas las circunstancias.

Otra cosa -discutible- sería decir que en «realidad» Ralws está comprometido con un sujeto concreto: un homo eoconomicus o un machista (no afectivo, independiente, autónomo, etc.). Pero en este caso la crítica lícita tendría que destacar su falsa universalidad, antes que su falsedad o su sesgo ideológico. Que la mecánica clásica no valga para cuerpos con velocidad próxima a la velocidad de la luz no quiere decir que sea falsa: sencillamente, no se refiere a tales situaciones. Por supuesto lo anterior no debilita, por ejemplo, la crítica feminista a buena parte de la teoría ética por su ignorancia de las experiencias morales, los valores, intereses y problemas que han encarnado y padecido las mujeres, pero invita a precisar el lugar (la reflexión, la teoría, o la realidad, el mundo) y la naturaleza (normativa o positiva) exacta de las críticas: que ignore un objeto de investigación no hace falsa o inconsistente a una teoría, sólo alude a cómo se desarrolla su aplicación. Por ejemplo, no se puede a la vez criticar la subordinación material de la mujer y criticar -por sesgada- una teoría normativa interesada en precisar la idea de autonomía: la primera crítica exige un punto de vista, la posibilidad de que la subordinación no exista, que es precisamente la idea de autonomía, idea que intenta perfilar la teoría moral. No se puede criticar la vocación de universalidad -sí la falsa universalidad- a la vez que se insiste en la importante distinción entre género y sexo, distinción que presume un principio de universalidad. Aún más no se puede sostener que, en sentido fuerte, las perspectivas teóricas están condicionadas por el sexo y criticar a las teorías normativas por sesgadas, cuando justamente -con esa calidadconfirman aquel juicio (en tal caso, ni siquiera cabría esperar que esa afirmación resulte inteligible para el otro sexo). 
simples sedimentos de sus circunstancias; d) errores de asunto, de objeto: la idea de un escenario en donde se contraponen preferencias tiene que ver con la negociación y el trapicheo de intereses y eso es precisamente carencia de cemento moral, pues es sabido que cuando hay moralidad bien afincada en la vida no hay conflicto ni por ende necesidad de convenir principios, procedimientos -como la idea de justicia- para resolver desacuerdos; e) errores de vacuidad o incluso de consistencia: la idea de una elección desde ninguna parte es irracionalidad o sinsentido; para elegir se necesitan criterios para comparar y valorar (no todo vale igual, aunque se pueda elegir de todo) y afirmar lo contrario es incurrir en la indeterminación moral, recalar en la creencia de que todo vale y por tanto desahuciar -singular paradoja liberal- desde el principio un -ya de por sí insensato- proyecto fundamentador cuya condición de posibilidad es que «se puedan dar razones en favor de».

\subsection{La argumentación historicista}

Las anteriores razones sugieren por donde irán las modificaciones de la $\mathrm{FH}$ en las dos dimensiones del PFD, en la idea de democracia y en el procedimiento de argumentación. Por lo pronto y en negativo, para la FH la democracia es cualquier cosa menos una herramienta, un escenario indiferente en donde los individuos muestran, reúnen o negocian sus preferencias. La democracia es una cultura en sentido fuerte, antropológico, un conjunto de conductas, de maneras de vivir que impregnan las decisiones de las gentes y que en su conjunto dotan de significación a las relaciones entre las gentes. La democracia es vida compartida, es valor sentido, valor en actuación. No es un sistema para dejar coexistir neutralmente los distintos valores, si no la encarnación de los valores de la comunidad: la democracia si es neutra deja de estar justificada (en el sentido de justificación que se verá: como intelección desde la circunstancia histórica). La democracia no es, tampoco, un procedimiento para determinar los buenos valores, sino un modo de -un valor que permite- estar en los valores. Garantiza la cohesión, pero no se justifica porque la garantice, sino porque los individuos la viven. La cohesión se alcanza porque no responde al cálculo, porque el compromiso con los valores es sentido. Participar de los valores de la comunidad puede tener consecuencias benéficas como la cohesión o la estabilidad emocional, pero sólo se obtienen tales beneficios si la participación es sincera, si se está en los valores sin calcular sus resultados. Resulta imposible decidir «sentir» los valores «porque de ese modo estaré mejor». No hay cálculo que haga útil, conveniente o interesante la democracia, precisamente porque los valores no se eligen o calculan por sus resultados. Tienen resultados porque no se atiende a los resultados.

Las gentes no conviven en la democracia, sino que viven democráticamente. Es cultura en grado superlativo, habida cuenta de que las distintas 
culturas se mueven en democracia. Pero no se trata de un concepto más abstracto, de una especie de metacultura, ni tampoco de simple escenario donde discurre la obra de la coexistencia de diferentes culturas. Es el argumento de la obra. La imagen no es la de una pecera en donde se crea un pequeño ecosistema, un habitáculo sin vida propia, lugar neutro, perfectamente sustituible, en donde transcurre la vida de sus pobladores, sino la de un organismo superior que, a la vez que organismo él mismo, es el ecosistema en donde encuentran su morada -patria, dirán muchos comunitaristas- otros organismos, que viven y contribuyen a la vida del primero, en interacción con él y con otros.

Varía el concepto y varía el procedimiento. Por lo dicho, malamente se puede pensar en una «fundamentación» comunitaria de la democracia. Al menos a la manera antes vista. Para la FH de lo que se trata es de entender la democracia y eso no remite a unos valores previos, más básicos. La única prioridad es histórica, genética, como la que se da entre la semilla y el árbol: éste no se deduce de aquella, aunque sea su resultado. No hay valor fundante, no hay axiomas anteriores, en sentido lógico, desde los que se muestre la bondad o funcionalidad de la democracia. La intelección se realiza desde un conjunto de valores que mutuamente se soportan e iluminan. Ni siquiera cabe decir que se «justifique por qué...». La idea misma de justificación está fuera de lugar. Es historia que se impregna como naturaleza y, percibida como tal, está más allá de la preguntas acerca de su justificación. Como el personaje de Casablanca «nadie se pregunta por qué respira»».

Pero sí cabe preguntarse «cómo se respira». Si la democracia es modo de vida, la tarea intelectualmente correcta es descriptiva, narrativa, antes que fundamentadora. Los planos analíticos no son ni internos a una única secuencia causal ni, por supuesto, jerarquizados. Sociología, ética y psicología se confunden y complementan al entender qué es la democracia. La posible comprensión «moral» de la democracia es radicalmente desde la historia y ésta es -para decirlo con las magníficas metáforas de Marx- totalidad determinada, síntesis de multiplicidad de determinaciones: no hay un principio moral (o una secuencia causal) fundamental que justifique (o explique), sino una red de valores y/o modos de vida que dibujan inflexiblemente la singularidad irrepetible de cada sociedad.

El «por qué democracia» no se contesta operacionalmente, sino desde «totalidades concretas», al modo del historiador ${ }^{41}$ : un historiador muy del diecinueve para el cual el correcto proceder se parece más al quehacer del artista que reproduce en otro soporte -en la narración reconstructiva- la misma «totalidad de sentido», que al del físico, que al científico que relaciona

${ }^{41}$ La descripción aquí realizada sintéticamente se corresponde con una estrategia explicativa que ha cuajado en una importante tradición del pensamiento social, el historicismo, en la que también se produce una parecida colusión de argumentos positivos, metodológicos y normativos (Ovejero, 1994a: primera parte). 
axiomas con teoremas. Tan solo en ese sentido se puede hablar de justificación: como la reconstrucción de la «necesidad interna» ${ }^{42}$ que alienta a cada circunstancia histórica específica. No hay prioridades, como no las hay entre las palabras que componen una lengua ni entre los elementos de una genuina obra de arte. Por eso, cuando después construimos un diccionario o un rompecabezas, las palabras o las piezas aparecen todas igualmente básicas, en soporte mutuo. En el mismo sentido, la democracia se entiende -y se sostiene- en una red moral que ayuda a sostener. Nuestro conocimiento intenta reproducir conceptualmente ese telar, esa singular combinación que dota de identidad a cada cultura. No hay, como en la perspectiva instrumental, una fundamentación que era, a la vez y mediada una inevitable teoría de la democracia, una estipulación: aquí no hay, en el sentido al uso, fundamentación; ni tampoco, dirían estos autores, estipulación, en tanto la democracia es, está, no se construye, ni conceptual ni instrumentalmente.

Por supuesto, la caracterización de la democracia como forma de vida es más bien magra. Pero como sucedía en el caso anterior, se trata de hacer justicia a perspectivas diferentes y reunirlas más que por sus tesis substantivas (una confusa amalgama de conjeturas históricas, tesis morales y principios epistemológicos $)^{43}$ por sus trazos metódicos y estrategias teorizadoras. En el presente caso «la forma de vida» expuesta resulta compatible con formulaciones de muy diversa inspiración: wittgensteinianas, para las que los individuos habitan -son, conviene insistiruna red cultural y lingüística, un juego de lenguaje, que dota de significado a comportamientos y elecciones; neoaristotélicas, que recrean -y no pocas veces fantasean- acerca de cómo eran las democracias antiguas; medievalizantes y organicistas, en las que se toman argumentos -acerca de vidas preñadas de sentido- del pensamiento reaccionario clásico, unas veces con resonancias escolásticas, otras directamente bíblicas y casi siempre con tonos nacionalistas-, o liberal-culturalistas, defensoras de la buena coexistencia entre gentes distintas, que reescriben nuestras democracias contemporáneas con tintes comunitarios, como

42 Este uso de necesidad es poco pulcro. Necesidad en su uso moderno, tiene un sentido bien preciso expresado mediante una cláusula modal («es necesario que»), el uso propio de la lógica o la matemática, como cuando, por ejemplo, decimos que «los teoremas se siguen necesariamente de los axiomas». El tipo de relaciones que interesan al historiador-narrador es, en todo caso, causal o funcional, y relaciona dos sucesos, no dos premisas. Si se retiene el uso extendido y licencioso es para atender la interesante intuición que hay detrás de la aspiración a rescatar la peculiar urdimbre que hace de cada sociedad un objeto único, una articulación irrepetible: intuición que se traduce en la búsqueda de un producto de conocimiento -que quiere reproducir aquel objeto- en el que cada pieza se convierte en única -al modo como sucede con las piezas de un rompecabezas- y sostiene y es sostenida por las otras. En ese sentido, metafórico, la «necesidad interna» es una necesidad derivada de una imposible necesidad de lo real: imposible, obviamente, porque son los enunciados, no los hechos los que, en todo caso, guardan relaciones de necesidad (ovejero, 1994a: cap. II).

${ }^{43} \mathrm{C}$ fr. infra. nota 46 y 47. 
un valor o identidad cultural que hace posible que distintas ideas de bien convivan sin tensión ${ }^{44}$.

\subsection{Los límites de la fundamentación histórica ${ }^{45}$}

La FH abandona cualquier ilusión trascendental, cualquier intento de asentar principios (morales, epistémicos o teóricos) desde los que anclar la argumentación. Los valores compartidos por la comunidad constituyen el límite de la razón práctica. Acciones y comportamientos se calibran por su ajuste a los valores de la sociedad en la que surgen. Los individuos se proveen de identidad como parte que son de la ciudad y su horizonte moral lo constituye la propia ciudad. Si no fuera porque alimenta la ilusión del sujeto trascendental, cabría decir que «los individuos están presos de la ciudad». Pero el sujeto es inevitablemente histórico y lo correcto es afirmar que «los individuos son ciudad». Como en el poema de Kavafis: «La ciudad irá en ti siempre. La ciudad siempre es la misma. Otra no la busques no la hay, ni caminos ni barcos para ti». La pregunta no es «¿qué quieres?» sino «¿quién eres?». Los individuos no eligen lo que son, sino que lo conocen, se (re)conocen. Frente a la antropología de consumidor, del individuo que «escoge» sus gustos, propia de la FI, la FH se queda con tipos como el enamorado, el creyente o el homo/heterosexual: a pesar del léxico viciado no se eligen -no hay«preferencias sexuales»; no se decide querer ni cabe la amenaza de dejar de querer; no se escoge creer en Dios. Los valores no se eligen, en los valores se está.

Sin embargo, la perspectiva historicista resulta menos brillante en sus tesis positivas que en sus críticas. Hay problemas muy de principio, en la frontera de la inconsistencia, derivados de la complicada coexistencia de tesis epistémicas, teóricas y normativas. Tesis de naturaleza bien diferente -que invitan a distinguir entre distintos comunitarismos ${ }^{46}$ - pero difíciles de

44 Desde un punto de vista propiamente metódico, la argumentación historicista se corresponde con el moderno coherentismo que con enorme brillantez ha rescatado bastantes de las intuiciones -aludidas en la nota 42historicistas, «narrativas», nego-hegelianas y de bastante historiografía marxista. Sobre el moderno coherentismo y sus distintas versiones cfr. Rescher (1973); Haack (1993: caps. 1 y 3).

45 Sobre la fantasiosa recreación comunitaria de las sociedades comunitarias, cfr. Phillips, 1993; sobre sus límites normativos y sus paradojas cfr. Kymlicka, 1988. Para una reconstrucción de Aristóteles de enorme calidad filológica y analítica poco del gusto comunitarista (sostiene y documenta, por ejemplo, la centralidad del concepto de derecho), cfr. Miller (1995). Vale decir que, en perfecta consonancia con lo apuntado en las notas 46 y 47, hay cierta paradoja añadida en ciertas estrategias comunitaristas de sugerir soluciones de entonces a nuestros problemas de hoy y, aún más, en exprimir las citas para parejo fin.

${ }^{46}$ Dificultades de esta naturaleza invitan a distinguir entre tres tipos de comunitarismos: una teoría política referida a los sucesos morales; una filosofía política que permite realizar valoraciones y fundamenta valoraciones; una -vulgar- teoría del conocimiento como un conjunto de ideas acerca de la naturaleza de las categorías analíticas. Distinciones que no salvan -sino que perfilan- las dificultades (Ovejero, 1995b). 
suscribir simultáneamente. Para ser más precisos, resulta complicado sostener que: (1) «la moral es el resultado de las condiciones históricas», tesis positiva acerca de la naturaleza de moral (un producto histórico); (2) «Las sociedades modernas son condenables por haber perdido -Como resultado de su propia desintegración- la conexión con ideas morales densas, como la virtud o la buena vida», tesis normativa; y (3) «no hay lugar para la condena moral suprahistórica, que requeriría una valoración transcendental de todo punto imposible habida cuenta el carácter inevitablemente contextual de las categorías analíticas», regla metodológica derivada de una tesis epistémica. La tesis (3) invalida la (2) y la (1), la condena y la universalidad. Naturalmente esa misma dificultad alcanza también a las ideas sobre la democracia. En el caso de la democracia -y la justicia- las tres dimensiones mencionadas se traducen en: a) la tesis de que la democracia -y la justicia- tienen que ver con escenarios de negociación, con mercadeo de intereses; (b) la crítica a la moderna democracia -y la justicia- de individuos atomizados porque nada tiene que ver con ideas como la virtud, la buena vida, la amistad o la religión; c) la crítica a los intentos de justificar «trascendentalmente» la democracia o la justicia.

Pero no es ésta la ocasión de explorar los problemas del comunitarismo, por más consecuencias que arrastren en su propia apreciación de la democracia. Ahora interesa sobre todo destacar como, con otros argumentos, la FH acaba recalando en dificultades parecidas a las de la FI: a) carece de vigor discriminatorio; b) vacía a la democracia de vínculos sólidos con la moralidad; c) recala en una antropología pobremente realista; d) coquetea con un nihilismo no muy diferente del que denuncia. Dificultades que invitan a pensar que tampoco ahora nos encontramos con una genuina fundamentación moral de la democracia.

1. La historia explica, no justifica. Dar cuenta de la pertinencia de la democracia como un modo de vida, narrar su funcionalidad dentro de -para los procesos que conforman una sociedad, no supone decir nada acerca de su bondad. Mejor, supone reconocer su bondad «respecto a aquello que existe». Eso justifica cualquier cosa, lo que existe por el simple hecho de existir siempre debe explicarse y, por ende, quedar fundamentado ${ }^{47}$. De manera que la $\mathrm{FH}$ carece de potencia discriminadora, incapaz de condenar nada, compatible con todo. Desde su inevitable contemporaneidad cualquier

47 Precisamente por eso la crítica comunitarista muestra las dificultades apuntadas al referirnos a la coexistencia de tres comunitarismos. El comunitarismo teórico explicaría la imbricación entre la moderna sociedad fragmentaria y las reglas de juego convenidas (democracia, justicia). Pero en tal caso, lo que no tendría sentido es el reproche del comunitarismo como filosofía moral por la pérdida de lazos, reproche que se mostraría inoportunamente trascendental, echando las cuentas desde criterios funcionales para otra -o cualquier- sociedad, que es precisamente lo que prohíbe el comunitarismo epistémico. 
cosa parece $\operatorname{bien}^{48}$. Y, claro es, cuando no hay posibilidad de discriminar, no hay valoración de nada. Tampoco de la democracia, que queda de ese modo fuera del horizonte de la reflexión moral.

2. No hay, por tanto, una vinculación fuerte entre democracia y moralidad. Tan solo hay circunstancial compañía temporal. Al modo como sucedía con la justificación instrumental, pero por otras razones, la democracia es superable, en la medida en que caduquen los nutrientes sociales e históricos que la alimentan.

3. La confianza en los valores no arranca de una consideración razonada que juzga imposible, por trascendental, sino del cobijo afectivo y referencial que proporcionan. Los individuos se sienten bien al participar de los valores de la comunidad porque son los valores de la comunidad. Pueden tener creencias «adecuadas» moralmente, pueden valorar la libertad o la igualdad, pero la raíz de su querencia es psicológica; no es electiva, porque los aprecien, ni tampoco es epistémica porque crean que tienen que ver con las buenas condiciones para la formación de los juicios. De otro modo: la elección moral «privada» desaparece -se disuelveen un proceso de causación social, de formación de las creencias desde lo público más propia de la psicología social que de la reflexión ética.

Las preferencias, que algo tienen que ver con la democracia, se desproveen de toda calidad moral. Los individuos andan presos de sus biografías. La correcta percepción de que siempre se elige desde alguna parte, de que no hay sujetos descarnados, se prolonga en la urgente inferencia de que no hay más: como nadie puede escapar a sí mismo, carece de sentido la aspiración a cualquier fundamentación, afincada en ninguna parte ${ }^{49}$. Eso es lo mismo que afirmar que no hay lugar para la elección de objetivos, para la elección moral. Si la FI vaciaba las preferencias de dimensión moral agotándolas en los gustos, la FH hace lo propio con la biografía. En el límite, los individuos determinados -sentenciados y abrumados- por su biografía, se muestran incapaces para la culpa y la responsabilidad. Sarmentosos de historia acumulada, autómatas de su propia historia y sin lugar para una elección genuina, resultan amorales. Como dice un buen poeta colombiano a propósito de los listos: «su misma certeza los aniquila».

48 En ese sentido -pese a Rorty- aparece comprometido con cierto realismo moral, en tanto acepta algo parecido a que los enunciados morales describen estados del mundo y son verdaderos con independencia de las opiniones de los individuos (Boyd, 1988).

49 Por esta vía la FH acaba coincidiendo con la tradición analítica más clásica. La vieja tesis intuicionista según la cual no hay posibilidad de fundamentar los juicios morales, que todo es una cuestión de adscripción a los valores, no está muy lejos de la tesis que afirma que no hay en la valoración otra cosa que historia o que la intuición no es más que educación y biografía. En todo caso, el comunitarismo, a diferencia de intuicionismo, añade una conjetura sobre el origen de las intuiciones: la historia. En uno y otro caso se produce la misma resignación, sea ante la propia biografía, sea ante el juego de intuiciones: no hay modo de escapar al «aparato moral de evaluar/percibir» $\mathrm{y}$, por tanto, no hay lugar para la calibración racional. 
Si la FI «resolvía» en gustos e intereses, que no permitían razones, la FH «resuelve» en historia, también impermeable a la racionalidad. En la FI, las preferencias, lo privado, por definición, era ajeno a la fundamentación y lo público era poco más que la agregación de las sinrazones privadas. En la FH la prioridad -aun causal- recae en la esfera pública: se forma sin atender a las voluntades de los individuos, las preferencias privadas se calibran por su adecuación a lo público y sólo porque lo público es público, compartido, no porque se valore y comparta. Para la FH los valores no se profesan, sino que identifican. Los valores compartidos proporcionan sentido e identidad a las gentes. En la perspectiva de la FH, el reconocerse como miembros de la comunidad otorga horizonte a los individuos y de esta manera, les proporciona confianza.

Confianza que no arranca de una elección razonada de los valores colectivos que, en el parecer comunitario, parecería presumir individuos anteriores a sí mismos. Así las cosas, el único resquicio para juzgar las preferencias es su ajuste a valores sociales densos (Williams), fuertes (Taylor), a la moralidad compartida.

Pero si las cosas son así, a fuerza de proporcionar certidumbres se desemboca en el escepticismo, cuando no en la inconsistencia. Pues, si es el caso que los valores no dependen de las elecciones, sino que son estas últimas las que se juzgan desde los valores compartidos, habrá que admitir la posibilidad de que los individuos se puedan comprometer en acciones que son valiosas aun si ellos no lo juzgan así, aun si no creen que, para ellos, tales acciones tengan sentido. Pero si yo no le veo sentido a una acción, no sé de qué modo podrá otorgar sentido a mi vida. Si los valores no dependen en alguna medida de las preferencias de los individuos, se hace difícil satisfacer precisamente aquel rasgo que se reconoce como más propio de los valores sociales compartidos, a saber, que para que un valor dote de sentido a la vida, para que se sienta, ha de ser creído. Para que una creencia proporcione norte a un individuo, es necesario que la haga propia, esto es, que tenga una relación sincera con ella, que se la crea (aun si es falsa o incorrecta). Para que Dios dote de sentido a mi vida, he de creer en él. Únicamente entonces experimentaré las consecuencias «benéficas» de una vida dotada de sentido ${ }^{50}$. Es en escenarios «vacíos de sentido», «alienados», desintegrados, en medio de la muchedumbre solitaria, donde me encuentro con individuos

${ }^{50}$ Con frecuencia en este terreno se maneja imprecisamente una palabra tan proteica como sentido con -perdón por el abuso- «sentido» (significado) diferente en distintos contextos. En todo caso, conviene recordar que: a) el que una creencia proporcione sentido (estado psicológico) a mi vida obviamente no quiere decir que la creencia tenga sentido (esté bien fundamentada, como estado metodológico); b) aun si la creencia tiene consecuencias psicológicas benéficas, la creencia no se suscribe por tales consecuencias benéficas; éstas son un subproducto de la propia sinceridad de la creencia: sólo porque la creencia realmente tiene sentido para mí, porque me la creo (estado epistémico), proporciona sentido a mi vida (estado psicológico). Pace Pascal, a cierto Pascal, no es posible creer -en Dios o en lo que sea- porque me conviene creer (por las ventajas aun si inciertas de la eterna salvación o por saber Dios qué).

Cierto es que a veces se afirma correctamente que «A cree en $\mathrm{x}$ porque le conviene» $\mathrm{y}$ existe sólida psicología social que muestra que muchas creencias se mantienen porque -en algún sentido- interesan. Pero conviene prevenirse de nuevo contra la falacia de la ambigüedad: el «porque» de la psicología social se refiere a las causas de la creencia; el «porque» que aquí nos ocupa es epistemológico, tiene que ver con las razones que fundamentan la creencia. En ningún caso A, preguntado sobre su creencia en $\mathrm{x}$, dirá que «le interesa creer en x». Es más, si contestase tal cosa, podríamos estar seguros de que no cree en x. La sinceridad es inseparable de la creencia, aun de la creencia que interesa tener. La creencia no admite la voluntariedad. No se puede, a la vez, afirmar sinceramente: «hay buenas razones para creer que es el caso que $\mathrm{x}$ » $\mathrm{y}$ «no creo que sea el caso que $\mathrm{x}$ ». Otra cosa es que existan buenas razones para aceptar la creencia. La aceptación conlleva, por así decir, un refuerzo epistemológico. De ese modo habría lugar para mantener creencias simultáneas que, sin embargo, no resultan aceptables. Para la distinción entre creencias y aceptación cfr. el brillante ensayo -muy Oxford- de L. Cohen (1992). 
autómatas, que realizan acciones sin sentido para ellos, aun cuando puedan tener otro "sentido» (productivo, p.e.) más allá de su voluntad. El comunitarismo, si no vincula de alguna manera la confianza en los valores a las preferencias de los individuos, se enfrenta una paradoja nihilista: por una parte, señala como rasgo constitutivo de los valores su condición de horizonte de sentido para las gentes y, a la vez, admite la posibilidad de individuos comprometidos en actividades valiosas, pero que están desprovistas de sentido para ellos mismos.

4. La crítica comunitarista de la $\mathrm{FI}^{51}$ arranca con antropologías cabales, con conocimiento social indiscutible: somos hijos de nuestro tiempo en nuestros gustos, elecciones y problemas. Tesis verdadera, acaso trivial pero, desde luego, desatendida por una tradición filosófica forjada en ilusiones trascendentales, en quiméricas aspiraciones a soluciones últimas y definitivas. La crítica comunitaria es solvente: la FI se muestra irrealista empíricamente. Ninguna conjetura, moral o empírica, puede ignorar aquel impecable supuesto antropológico. Incluso la afirmación más arriesgada según la cual las gentes conforman sus identidades en el lenguaje, que le proporcionaría una manera de conocerse y reconocer, es una imprecisión no exageradamente insensata. Nadie duda de que configuramos nuestra identidad en el

51 Este argumento crítico, el «problema del liberalismo y el bien» (Douglas, Mara, Richardson, 1990), se extiende más allá de la idea de democracia. En su versión habitual afirma que el liberalismo se encontraría en dificultades para conciliar su agnosticismo respecto a la idea de bien, el ideal de imparcialidad que inspiraría a la democracia liberal, con la defensa de sus ideales (libertad, cierta igualdad elemental) y/o con la crítica a los idearios intolerantes, totalitarios o integristas. En una formulación más precisa la dificultad compromete a tres aspiraciones que cuajan en tres argumentos de complicada coexistencia: a) el ideal de imparcialidad que lleva a sostener que todas las ideas tienen igual valor; b) la adscripción a algunas de ellas y la consiguiente afirmación de las ideas liberales; e) la racionalidad de esa adscripción, esto es, la afirmación de que hay razones para pensar que unas ideas son mejores que otras. 
espacio de relaciones en el que estamos ${ }^{52}$. Nuestra historia es nuestra jaula de hierro. Pero la historia no acaba ahí.

Porque es desde ahí desde donde elegimos. Que un individuo tenga unas preferencias y que éstas constituyan su identidad, no quiere decir que no pueda revisarlas racionalmente. Tampoco hay aquí novedad ni tarea titánica. También estamos instalados -incluso biológicamente- en otros escenarios y nos mostramos capaces de revisarlos: nuestro aparato neurosensorial solo reconoce ciertas longitudes de onda, nuestra experiencia cotidiana es la propia de la física aristotélica. No sería exagerado decir que las creencias que conllevan tales experiencias están ancladas biológicamente, que tienen valor de supervivencia ${ }^{53}$. Sin embargo, aun instalados en ellas, hemos sido capaces de revisarlas. Precisamente es la existencia de lenguaje, la razón o la ciencia la que nos permite escapar a las limitaciones de la percepción, la intuición y aun de la imaginación. No podemos imaginar espacios de más

52 Este juicio tiene más textura que una vulgar sociología. No se trata simplemente de que la «sociedad nos influya». Por supuesto que incluso en un escenario de negociación los individuos forman su carácter como consecuencia de sus relaciones, aun cuando «entren» en la negociación con las ideas claras y no dispuestos a ceder un milímetro de sus intereses. Pero se trata de algo más. Se trata de lo que, por ejemplo, sólo encuentra su realización más consumada en una idea cabal de relación amorosa. En ésta, los individuos, que por supuesto tienen carácter y no negocian su identidad, están dispuestos a revisar ésta y modificar aquél a la luz de las buenas razones, desde la apreciación de lo que parece bien, desde lo que se quiere ser, y a la luz de los argumentos de un «otro» que, en la medida en la que inevitablemente está en lo mismo, también se configura desde el primer juicio. Mejor juicio que se convierte en la razón de la actuación, pues no se «colabora con el otro» a la espera de contraprestaciones, por un intercambio negociado de intereses, no se actúa instrumentalmente, a la espera de algún resultado (agradecimiento), sino que la actuación -la ayuda, la cooperación- tiene en ella misma su retribución. En buena medida, la relación es parecida al tipo de relación que tenemos con nosotros mismos: uno no negocia, no se divide sus ingresos según sus aportaciones, no busca compensaciones, se tienen -o se intentan tener- ciertas ideas acerca de lo que se quiere y de lo que está bien (aun si unas veces con mayor intensidad que otras o con preferencias conflictivas, pues no todo se puede hacer a la vez); aunque, obviamente, en la relación amorosa hay más densidad y menos facilidades -porque las razones son públicas y la exigencia permanente- para el autoengaño y la resignación (Darwall, 1988). No escapará al lector el trasfondo aristotélico de estas consideraciones, cfr. Annas (1993: 249-ss); Nussbaum (1990: 55-105); Sherman (1989: 119-ss): Doménech (1989; 1993; 1995). (No creo que haya que atribuir a la casualidad la abundante presencia de mujeres -desde Arendt (1959)- en la recuperación de Aristóteles en clave «virtuoso-analítica» (Foot, 1978: Rorty, 1980) o republicana (Elshtain, 1981: Dietz 1985), claramente opuesta a la clásica, reaccionaria y elitista, acuñada por Strauss (1964)).

53 Hay evidencia suficiente para mostrar que nuestra física terrestre es aristotélica -con sus arriba, abajo; con sus cuerpos que caen por su peso, etc.- y que resulta eficaz evolucionariamente (McCloskey, 1983). Otro tanto se podría decir de la tan denostada «piscología popular», de la atribución de intenciones, deseos, creencias. etc. Hasta los más duros eliminacionistas aceptan la eficacia de la «folk psychology» para nuestra experiencia cotidiana (y apenas se atreven a sugerir qué pasaría si «el sofisticado vocabulario de la creencia se generalizase» Chuchland, 1995: 335). Para una inteligente comparación entre física popular y psicología popular cfr. Dennett (1991). 
de tres dimensiones; tampoco podemos tener imágenes del comportamiento de buena parte del mundo subatómico y sin embargo, podemos construir (teorías sobre) espacios n-dimensionales y disponemos de la mecánica cuántica. En todos esos casos, ese lenguaje -artificial como todosque es la ciencia nos permite escapar a biografías absolutamente densas y fuertes, inscritas en nuestro aparato neurosensorial, a biografías de millones de años.

Nos situamos en una física falsa, experimentamos nuestras percepciones cotidianas desde ella, y no por eso estamos impedidos para reconocerla críticamente. Escapamos a las creencias en las que naturalmente parecemos instalados, y apostamos por nuestras mejores creencias, por aquellas que, aun si no se amparan en nuestras experiencias biográficas o biológicas, se muestran bien fundamentadas, se han formado de acuerdo con ciertos patrones de racionalidad y experiencia. Ese es el asunto: el correcto procedimiento que asegura las mejores creencias. Si las cosas son así en escenarios a los que estamos -por así decir- cosidos biológicamente, no se ve qué dificultad hay en reconocer que uno está en ciertas ideas y, a la vez, admitir la posibilidad de escapar a ellas, de preguntarse por la propia vida, por cómo revisar las preferencias y, a su través, por la propia identidad.

\section{La democracia como principio ${ }^{54}$}

Si resulta como lo hemos estado pintando hasta aquí, escasas simpatías tendrá nuestro colega por la tercera de las perspectivas, por la FE. En una mirada urgente, le parecerá que, a pesar de su pretenciosa adjetivación, la perspectiva epistémica es antes que otra cosa una perspectiva metafísica, comprometida como parece estar con una defensa esencialista de la democracia, con una especie de inmortal principio democrático que no atiende en exceso a la historia ni parece depender de la maximización de nada, de la obtención de ciertos resultados. Las perspectivas anteriores estaban dispuestas a reconocer la caducidad de la democracia, sea porque ya no sirve como herramienta decisional o porque hay otra mejor, sea porque prescribió con los modos de vida que la alimentaban, mientras que para la FE la democracia tiene bastante de principio irrefutable, impermeable a los estragos del tiempo. La democracia no parece subordinarse a nada, antes bien,

54 Bajo este rótulo se recoge la fundamentación epistémica y la -correspondiente- teoría de la democracia (republicana, deliberativa). Cfr. Cohen (1986; 1989); Manin (1987; 1995); Fishkin, (1991); Gargarella (1993; 1995); Habermas (1988); Beitz (1989); Barber (1984); Miller (189: cap. 10); Estlund (1993); (Nino, Rosenkrantz (1991), Pettit (1989); Sunstein (1989). Se trata de líneas de argumentación diferentes, unas veces referida a la idea de democracia (republicana) y otras a las vías de fundamentación (epistémica). Pero el núcleo argumental que se reconstruye a continuación no traiciona en exceso a nadie. 
es palabra última, criterio de calibración antes que instrumento a ser medido por patrones más fundamentales ${ }^{55}$.

Para la FE, la democracia sería buena cosa, pero ¿buena cosa, sin más? Desde luego no cabría dar razones ulteriores, al menos a la manera de las justificaciones instrumentales: porque sirve para $\mathrm{x}^{56}$. Si así fuera, ya conocemos la consecuencia: habría que estar dispuestos a admitir que acaso algo distinto de la democracia puede servir mejor para obtener x. Pero para la FE tal juicio resulta inaceptable. La democracia es básica, no discutible,

55 Pudiera parecer que la FE se refiere a defensas deontológicas de la democracia y que la primera perspectiva (la FI) se refería a defensas consecuencialistas. Sin embargo, la presente discriminación no atiende fundamentalmente a un criterio de estrategias de argumentación normativa. Otra cosa es que las dos discriminaciones resulten coextensivas, que las teorías instrumentales utilicen argumentos consecuencialistas. Siempre cabría imaginar una argumentación deontológica que sustituyese «la democracia produce la maximización de -el valor- x» por «la democracia encarna máximamente el valor $\mathrm{x} »$, sin modificar el carácter instrumental de la fundamentación. El compromiso deontológico es con -el valor- $\mathrm{x}$, no con la democracia. Si otro sistema encarnase mejor que la democracia el indiscutible valor $\mathrm{x}$, la democracia quedaría superada. La instrumentalidad no radica en la «maximización», simple conjetura empírica. En todo caso, no quisiera escamotear la especial provisionalidad de estos juicios.

${ }^{56}$ Conviene recuperar (nota 2) de nuevo la distinción entre teorías de la democracia y fundamentación de la democracia que puede iluminar ciertas polémicas en torno a la democracia republicana. Elster (1986a; 1986b) ha criticado con pertinencia ciertos enfoques (Arendt, 1973) de la «democracia como autorrealización» que olvidan que para que realmente una tarea resulte autorrealizadora ha de servir para algo, que la autorrealización es efecto lateral o subproducto de la realización: es porque mi obra resulta ajustada a (mi) propósito por lo que me siento realizado. En ese sentido, dice Elster, la democracia será autorrealizadora en la medida en que ayude a tomar decisiones, mientras sirva para algo (aunque sería mejor decir: «mientras se crea que sirve para algo»). Eso es indisputable. Pero hay un extremo en el «deontologismo» (antiintrumental) de los defensores del foro, que la crítica de Elster corre el peligro de escamotear, extremo que la distinción entre teorías y fundamentaciones ayuda a aclarar. En el plano teórico se trata de discutir qué es la democracia y en esa discusión está comprometido tanto si la democracia es un buen sistema para tomar decisiones como si la democracia tiene interesantes subproductos. Ambas son discusiones estrictamente empíricas. En el plano de la justificación también cabe referirse a tales asuntos -una vez se ha visto que los juicios son ciertos- para justificar la democracia. Lo que no cabe reprochar es que se haga uso en un plano normativo del argumento de la autorrealización. El que ésta sea un subproducto y no se pueda perseguir directamente, es asunto empírico. Pero desde el punto de vista normativo no hay ningún problema -en principio- en apelar a los resultados laterales para justificarla. Una cosa es que esté condenado al fracaso perseguir directamente, es asunto empírico. Pero desde el punto de vista normativo no hay ningún problema -en principio- en apelar a los resultados laterales para justificarla. Una cosa es que esté condenado al fracaso perseguir directamente lo que es un subproducto y otra el que algo se justifique, aun si no consigue sus resultados no laterales, por sus subproductos. Aun si la acción o el proceso A no permitiera obtener máximamente x (conjetura empírica), yo podría defender $\mathrm{A}$ porque la búsqueda de $\mathrm{x}$ a través de A -y sólo a través de A-permite obtener $\mathrm{z}$ (carácter, bondad, perseverancia). Por lo demás, no está nada claro que el reconocer la condición de subproducto de algo nos impida perseguirlo a sabiendas de lo que hacemos. En particular esto es así en bastantes escenarios políticos. Cfr. las críticas de Chan y Miller (1991) a la teoría de los subproductos de Elster en sus juicios sobre la democracia republicana. En ese trabajo los autores reconocen diversos grados de imposibilidad para perseguir y obtener los subproductos políticos. Asimismo sobre lo razonable de los objetivos inalcanzables (Rescher, 1987), cfr. infra nota 67. 
fundante: no hay razones ulteriores que la cimienten. No solo es que no sea superable, es que la misma idea de superación resulta un sinsentido, no se sabe muy bien qué quiere decir. Afirmar que no cabe la superación equivale a afirmar que la justificación que se hace de la democracia solo sirve para la democracia. Se puede decir que el vínculo que la FE establece entre moralidad y democracia no es una relación circunstancial, que se trata de un vínculo necesario.

El propósito no parece asunto menor. Por una parte se sostiene la calidad insuperable de la democracia, o lo que es lo mismo, que la justificación de la democracia es exclusiva. Pero a la vez se mantiene el propósito fundamentador. Y es el caso que la idea misma de fundamentar parece remitir a un valor ulterior, más básico, desde el que se fundamenta. Desde una perspectiva inferencial, la relación entre el valor fundamentador y lo fundamentado es de la misma naturaleza que la que guardan axiomas y teoremas; y ya se sabe como funcionan ese tipo de relaciones, no hay vínculos de exclusividad: un conjunto de axiomas, en principio, permite generar infinitos teoremas; un mismo teorema puede inferirse desde distintos conjuntos axiomáticos. Así las cosas, la vinculación entre el valor fundamentador y la democracia difícilmente se puede pensar como una función biunívoca en sentido matemático: de uno a uno. En suma, no resulta asunto baladí compatibilizar la idea de fundamentación con la razonable intuición de la insuperabilidad de la democracia.

De todos modos, alguna razón habrá que dar si no se quiere incurrir en deontologías metafísicas, en afirmar la bondad esencial de la democracia, lo que equivaldría a abandonar el asunto mismo del PFD. Se trata, pues, de mantener la idea de fundamentación pero sin que esa fundamentación acabe tomando la forma de «porque permite $\mathrm{x}$ ». La solución podría estar en una justificación que no recalase en un valor ulterior, sino, por así decir, en un valor simultáneo, en una especie de «porque la democracia es $\mathrm{x}$ » $\mathrm{O}$ «porque la democracia equivale a $\mathrm{x}$ ». A algo parecido a esto parecen referirse los defensores de la FE cuando aducen que la democracia equivale al ejercicio de la eticidad, a las condiciones para determinar «los buenos valores». No se trataría en tal caso de una fundamentación desde otro valor (más básico), interna, sino desde otro plano, el epistémico. Precisamente esa calidad «externa» impide encallar en uno de los escollos a los que se enfrentó la FI: que la sustitución de «porque permite $\mathrm{x}$ » por un «porque es $\mathrm{x}$ » (o el más preciso: «porque equivale a $\mathrm{x}$ ») desemboque en tautología, en una pseudosolución que se limita a estipular por definición que «la democracia es lo mismo que $\mathrm{x}$ ».

\subsection{La argumentación epistémica}

El empeño, aunque complicado, no es original. Una comparación puede resultar iluminadora. Asuntos que han entretenido a la reflexión filosófica, 
como la ciencia o la razón, parecen participar de esa singular cualidad que hace que resulten interesantes, que produzcan buenos resultados, pero que no se justifican estrictamente por sus buenos resultados, entre otras razones porque con frecuencia yerran; ni tampoco se justifican trascendentalmente, desde principios más fundamentales. Antes bien, razón y ciencia, ellas mismas, fundamentan. Cierto es que nos ayudan a conocer el mundo o a tomar decisiones correctas; pero si tales resultados no son sin más su justificación es porque no son independientes de su ejercicio. Sencillamente no sabríamos muy bien de qué otro modo podríamos funcionar, no sabríamos que significa disponer de un conocimiento veraz o tomar una decisión bien fundamentada que no tenga que ver con la ciencia o la razón. Estamos instalados en ellas, constituyen la gramática de cualquier lenguaje que quisiéramos manejar y los necesitamos para entender, para evaluar, para saber que cierta afirmación es un conocimiento bien fundado o una recomendación correcta. En ese sentido, aun si avalados por sus resultados, sirven a la vez para avalar.

La FE arrancaría con argumentos parejos en el terreno de la fundamentación de los juicios morales. Mientras podemos concebir la toma de decisiones o la maximización del bienestar -un dictador ilustrado y benevolente, interesado en el bienestar objetivo de las gentes, que conoce y satisface sus deseos reales- sin la democracia, no podríamos concebir la idea de elegir una idea de buena vida que no pase por ciertos requisitos que tienen que ver con cierta idea (republicana) de la democracia: autonomía, información, argumentación pública, disposición a revisar juicios. Idea que es bien diferente de la democracia competitiva. Frente a la democracia como la simple reunión de voluntades prepolíticas, de intereses que, por definición, no admiten argumentación pública ni modificación, la voluntad general republicana es a la vez un proceso de agregación y de formación pública -política- del juicio, abierto al análisis y la réplica, a la justificación razonada de las opiniones, a la revisión de las preferencias.

Revisión de prefencias que implica revisión de la identidad de los individuos. Y aquí se evitan las dificultades de la FH. Como correctamente señalaba ésta, los individuos no trascienden -son distintos de- sus características, su identidad no es previa a sus preferencias. Pero precisamente en virtud de esa condición de nudos de preferencias, en la medida misma que las preferencias son susceptibles de revisión racional, las identidades se pueden modificar cuando se revisan las preferencias. Una vez se asume una idea realista de los sujetos, hacer de la actividad política materia de diálogo racional equivale a admitir que aquella actividad tiene que ver con la automodelación: la elección racional de las preferencias es elección racional del carácter. Y no hay que olvidar el punto de partida: entrar en diálogo con sinceridad necesariamente compromete con la disposición a cambiar el propio juicio. Sostener que mi juicio es correcto supone admitir que es defendible con razones. Al invocar razones reconozco que mis preferencias están subordinadas 
a un tribunal que muy bien puede mostrar -a mí, que soy el que lo invoca- que estoy equivocado: mi compromiso no es con las preferencias, sino con la argumentación que la fundamenta. En ese sentido, rectificar un juicio es, en rigor, confirmar la corrección de mi sistema de fundamentación. Una vez se reconoce que las preferencias están equivocadas, es obligado revisar las anteriores, evaluar la propia vida ${ }^{57}$.

Como se ve, también ahora el cambio en el proceso de fundamentación arrastra un cambio en la idea de democracia. La democracia republicana encuentra defensas diversas ${ }^{58}$, pero por detrás de ellas cabe reconocer un núcleo

${ }^{57}$ Por supuesto, hay aquí implicados interesantes procesos psicológicos, que invitan -sobre todo en estos tiempos de sólidas corrientes naturalistas en epistemología y filosofía de la mente (infra. nota 66)- a evitar la urgente contraposición entre psicología y racionalidad. Contraposición que acostumbra a recordar importantes resultados de la psicología social (disonancias cognitivas, wishful thinking, etc.- que llevan a dudar de la racionalidad en la formación de creencias y deseos (Para un repaso reciente, cfr. Sutherland, 1994). Sin embargo, conviene precisar algunas cosas. La primera: mucho comportamiento calificado como irracional (akrasia, preferencias cambiantes, compulsiones) lo es menos mirado de cerca, tiene, no sólo su razón de ser, sino que oculta una racionalidad inobservable superficialmente (cfr. el magnífico -aunque exagerado- trabajo de Ainslie, 1992). En segundo lugar, la mayor parte de tales resultados se refiere a la influencia de la comunidad en la formación de juicios y opiniones individuales (a la influencia social "dentro de mi cabeza»), que es precisamente lo que se quiere conjurar en una discusión compartida y comprometida con razones: las racionalizaciones se dificultan notablemente en un diálogo sinceramente expuesto a réplicas. En tercer lugar, no hay que olvidar que esos mismos procesos con frecuencia son de doble dirección. Al cabo, las disonancias cognitivas se corrigen modificando una de las dos creencias. Cabe pensar que en una atmósfera sin telarañas mentales el juicio a corregir será el que no se ajuste a los compartidos -y bien fundados- patrones de racionalidad. Por último, no hay intento de justificación (Pratkanis, Aronson, 1992: cap. 3). En todo caso resulta bien cierto que en el tratamiento habitual de los procesos de formación de las preferencias por parte de la filosofía política hay cierto descuido de los mecanismos psicológicos implicados, descuido injustificado, pues, como ya se dijo, el que una teoría sea normativa no la exime de manejar supuestos compatibles con la información disponible.

58 Las defensas del diálogo frente a la negociación al servicio arrancan de objetivos diferentes no siempre suficientemente discriminados: determinar la verdad moral, obtener los juicios morales más adecuados, detectar los intereses compartidos, descubrir los propios intereses, desarrollar las virtudes, determinar una idea de buena vida, determinar las reglas justas. No es la presente la ocasión de discriminar en la amalgama de argumentos no pocas veces demasiado fascinados por el consenso (algo de eso hay en el Rawls más reciente (1993)). A la hora de inyectar realismo buenas son las páginas que Rescher (1993) dedica a criticar la estrategia de la argumentación ideal o consensuada y las que Elster (1994) entretiene en explorar la tensión entre argumentación y negociación en escenarios reales: la Convención Federal de Filadelfia y la Asamblea Constituyente del París revolucionario.

A propósito de la complejidad de argumentos aludidos quizá convenga recordar cierta inconsistencia pragmática presente en algunas defensas de la democracia directa que apelan a los intereses excluidos. En ese mismo sentido no se puede ignorar que aún si defiende ambos una democracia de competencia -y representativa- no son los mismos los argumentos de Madison (1961: Federalist 10), que apelan a buenas razones (versus intereses) susceptibles de ser argumentadas, que los de Sieyes, quien invoca a los costos de la actividad política en el capitalismo («Observaciones sobre el informe del Comité de constitución acerca de la nueva organización de Francia», 1879 (Sieyes, 1993: pp. 219-ss)). La ambigüedad de la inspiración de los argumentos «democráticos»cfr. por ejemplo la veta aristocrática de «desprecio a la mediocridad» detectada por Kahan (1992) en Burckhardt, Stuart Mill y Tocqueville) invita más que nunca a deslindar el terreno normativo (la fundamentación, propiamente dicha), la explicación histórica de lo que acontece (p.e.: el común argumento de la operatividad en favor de la democracia indirecta es historia ficción retrospectiva) y el psicológico-motivacional (la intrahistoria de las razones de los clásicos protagonistas). 
compartido que equipara -las condiciones de- la democracia a la buena formación de los juicios morales. La discusión, la defensa pública de las opiniones que obliga a asumir imparcialidad, la disposición a revisar las preferencias, la igualdad de -las voces del- los individuos en el foro ${ }^{59}$, conforman un conjunto de procedimientos que, sin tener que ver propiamente con juicios éticos, permiten acercarse a las mejores opiniones éticas. Desde ahí los caminos se diversifican, según la opinión que se tenga sobre la ética (y aún sobre la ciencia) ${ }^{60}$. Para unos la democracia permite determinar las verdades morales, para otros las creencias morales correctas.

Parece más razonable suscribir la segunda de las opiniones, sin dejar de advertir que ello no supone alejarse del paralelo con la ciencia. De nuevo la comparación resultará iluminadora, en particular esa opinión común según la cual la ciencia nos permite conocer -o avanza en el camino a- la verdad (o la realidad). Aunque no sabemos muy bien hacia donde se dirige, ni en qué consiste, ni cual es la forma que toma, todos estamos de acuerdo en que existe el progreso científico. En rigor se trata de una idea que está asociada al concepto mismo de ciencia, a la fundamentación -y por tanto a la revisión- del conocimiento científico ${ }^{61}$. Aun si abandonamos conjeturas caducas, si nos quedamos en mitad de la inseguridad, reconocemos en ello un progreso. Sabemos que la ciencia avanza unas veces contestando preguntas y otras, más importantes, descalificando preguntas (¿cuánto pesa el calórico?, ¿cuál es la densidad del éter?) que resultaban pertinentes para las viejas teorías pero que ahora son puro sinsentido. Del mismo modo, la mayor parte de nuestro conocimiento actual está llamado a ser juzgado falso. Por eso no cabe afirmar sin matizar que conocemos la realidad o que nuestras teorías son verdaderas. Lo que sí podemos decir es que nuestras teorías actuales son las mejores que podemos disponer a la luz de lo que sabemos. Así las cosas, el acento recae menos en la «verdad» de las creencias empíricas que en su buena formación. Nuestras teorías son las mejores porque se han construido del mejor modo: consistentes, acordes con las observaciones, compatibles con otras teorías más básicas, etc. Como no disponemos de un

${ }^{59}$ Que como ya se dijo (nota 34 ) no es simple igualdad de voto. Es reconocer la igualdad de voces y la posibilidad de diferente excelencia, sin que eso tenga traducción en desigualdad de posibilidad de ser escuchado, cosa que sí sucede, por ejemplo, con la desigualdad asociada a las propiedades de los medios de manipulación de masas. Cfr. Dworking, 1990.

${ }^{60}$ Cfr. infra nota 63.

${ }^{61}$ Sobre la idea de progreso científico cfr. Rescher, 1984; Niinluoto, 1984. 
criterio independiente de verdad, de la posibilidad de mirar la realidad por detrás de la ciencia, solo podemos fiarnos de ese instrumento, la ciencia (y en general la razón), a sabiendas de que a veces nos confundirá, pero con la seguridad de que es nuestro único asidero, de que ni siquiera podemos imaginar un modo de obtener conocimiento que no tenga que ver con un conjunto de procedimientos, con eso que llamamos ciencia o razón. Un Dios de buen dispuesto entendimiento que nos enviase teorías verdaderas pero no nos dijera nada acerca del cómo de las teorías nos resultaría incomprensible ${ }^{62}$. Entender los mensajes de ese Dios requeriría aplicar a sus juicios criterios de racionalidad, calibrar desde alguna elemental idea de ciencia ${ }^{63}$.

Pues bien, mutatis mutandis, algo parecido se podría decir acerca de los juicios morales y la democracia. Metafísicamente, en el mismo buen sentido de la palabra, se podría decir que caminamos detrás de alguna idea de verdad moral y que en ese trajinar avanzamos plagados de incertidumbres en el progreso moral ${ }^{64}$, pero sin tomarse demasiado en serio las palabras, al menos para describir nuestro presente o cualquier presente. Sencillamente,

${ }^{62} \mathrm{Si}$ un Dios ilustrado -y un poco vanidoso- se decidiera a comunicarnos enunciados de buena ciencia, la simple intelección de que se trata de verdades sobre el mundo y no los versos de un deslabazado poema requeriría el uso de la razón, que los examinásemos según los procedimientos disponibles: si se ajustan a las observaciones, si los términos que emplean son entendibles, esto es, compatibles con lo ya sabido; en suma, exigirían utilizar el mismo proceder que aplicamos a las conjeturas candidatas a formar parte de las teorías científicas interesantes, eso que en épocas de arrogancia positivista se llamaba «método científico». Si Moisés hubiera bajado del Monte Sinaí con enunciados del tipo: «fuerza es igual a masa por aceleración», «el hipotálamo participa en la regulación de los sistemas neurovegetativo y endocrino» lo habrían encerrado. Si en lugar de inspirar la Biblia, Dios se hubiera decidido él mismo a escribir algo así como el magnífico Diccionario de teorías científicas de J. Bothamley (1993) no habría encontrado editor.

${ }^{63}$ Los juicios anteriores no están comprometidos obligadamente con una idea operacionalista o pragmática de la verdad, según la cual la verdad se agota en su procedimiento de obtención. Dicho de otro modo: son compatibles también con separar la idea de verdad y el procedimiento de obtención, con la distinción entre «qué hace a una proposición verdadera» y «cómo determinamos que es verdadera». Lo único que se afirma es que no hay un modo de determinar la verdad independiente de los procedimientos de la ciencia. Sobre las teorías de la verdad cfr. el insuperable trabajo de Kirkham (1992). Pues bien, como se argumenta a continuación, lo dicho vale también para nuestro asunto y en ese sentido la FE no está comprometida con una única teoría acerca de la naturaleza de los asertos morales. Ello no quiere decir que no excluya nada. Es más, la superación de la democracia para la FE resultaría imaginable desde dos premisas: a) existen «verdades morales» con independencia de su determinación por la democracia; b) existe un procedimiento para esa determinación independiente de la democracia. En tal caso se podría prescindir de la democracia. Lo que sucede es que la FE añade: «no se sabe qué querría decir un modo de determinación independiente, en tanto cualquier candidato (Dios) se vería calibrado para su simple inteligibilidad por los procedimientos de racionalidad práctica que toman cuerpo en la democracia».

${ }^{64}$ La comparación entre progreso moral y progreso científico tiene sus límites. La primera: mientras que progreso científico afecta a nuestras herramientas conceptuales o, en todo caso, a los efectos de ese progreso sobre la tecnología, lo que llamamos progreso moral no se refiere a las teorías morales sino a los procesos sociales. Confundir el progreso moral con el progreso -nada espectacular- de nuestras reflexiones morales es un hermoso pecado de arrogancia tan ilustrado como escasamente sensato, bastante común, por demás, en individuos que traslegan poco con la vida extraacadémica. La otra diferencia, muy importante y llena de consecuencias, tiene que ver con la circunstancia de que el progreso afecta a las intuiciones morales, esto es, al material observacional -evaluador- de las teorías éticas. Desde luego, en ningún sentido epistemológicamente cuando se puede decir que el progreso de la ciencia es disponer de nuevas observaciones que modifiquen las anteriores. 
tenemos las mejores creencias posibles porque esas se han construido del mejor modo posible, de un modo autónomo no arbitrario. Y ese mejor modo incluye una evaluación discursiva, dialógica y racional. Los ciudadanos republicanos sostienen sus juicios en razones públicas, esto es, revisables, y con ellas, reconsideran sus propias elecciones. Saben que vienen de alguna parte, que tienen identidad, pero no son -para decirlo con Carpentier- simples cuerpos de carne transcurrida: están en condiciones de revisar sus juicios y sus preferencias. En tanto suscriben sus juicios porque les parecen bien fundados, no les resulta imaginable -cosa que sí sucede en la FI- un «bienestarismo objetivo» que determine con independencia de su opinión, las «verdaderas preferencias colectivas». Sencillamente no hay un modo independiente de determinar la voluntad general que la voluntad de todos formada desde las buenas razones. Y, al fin, eso es la democracia republicana ${ }^{65}$. Idea de democracia (deliberativa, republicana) y de fundamentación que permiten salvar aquellas dificultades que impedían reconocer una auténtica cuestión de racionalidad práctica en las FI y en la FH y en sus respectivas ideas de democracia:

1. Reconoce un genuino problema de fundamentación. La FI entendía la democracia únicamente como una herramienta para tomar decisiones. La dimensión moral se limitaba al propósito para el cual servía la democracia

65 Desde esta perspectiva, amén de disponer de un apunte de solución a la paradoja liberal, se hacen inteligibles propiedades que de un modo impreciso se han asociado a la participación democrática -como es el caso de la autorrealización- que para cierto republicanismo constituyen la justificación de la democracia (cfr. supra nota 56). No se trata de que la participación sea un goce, sino de que el ciudadano -cuando participa seguro de que se compromete por que está convencido de lo que hace, porque hace lo que tiene que hacer- se experimenta guiado interiormente y a la vez de acuerdo con otros (autónomamente) y eso siempre proporciona serenidad. Aun en el desconsuelo y la derrota, la racionalidad, además de asegurarnos la mejor o la menos mala de las opciones, nos otorga la lúcida calma que acompaña a la certidumbre de que no hay otro modo de actuar. Como se apuntó en la nota 57, es falaz contra poner incondicionalmente racionalidad y psiquis. Los procesos de participación en los que uno se reconoce convencido y por tanto dispuesto a modificar juicio, tienen poco que ver con las racionalizaciones patológicas de quienes tienen que pactar con sus intereses y se resisten a reconocerlo. Se parecen más a la serenidad con la que nos pensamos en la buena relación amorosa (cfr. supra nota 52). Conviene, además, no desatender que la disposición a actuar aumenta cuando la participación se hace con convencimiento, por buenas razones y porque se cree que es lo que se debe hacer. Esta circunstancia resulta particularmente importante habida cuenta de que la democracia republicana requiere ciudadanos activos. Esto constituye un rasgo diferencial frente a la democracia de intereses, competitiva, que entiende la actividad política como un coste, como un fatigoso quehacer instrumental que debe ser retribuido; democracia competitiva que, como corresponde a esa circunstancia, se alimenta de ciudadanos pasivos (Ovejero, 1994a: caps. 4 y 5; 1995b). 
(la maximización de la utilidad, p.e.), al valor que hay detrás de la herramienta (el bienestar), y a su justificación; de ninguna manera hacía de la propia democracia el territorio de la reflexión moral. Por su parte, la FH veía en la democracia simple historia y la historia se explica, no se justifica. La FE, como se acaba de ver, sitúa a la democracia en el corazón mismo del problema clásico de la materia moral: Las condiciones de fundamentación de la racionalidad práctica.

2. Proporciona una genuina justificación, esto es, que abarca a la democracia y únicamente a la democracia. Tanto la FI como la FH justifican demasiado y demasiado poco. Para la perspectiva instrumental la democracia es un simple mecanismo para tomar decisiones. En ese sentido, como se dijo, si encontráramos otro instrumento más eficaz, deberíamos abandonar la democracia. Por su parte, la perspectiva comunitaria da cuenta de la democracia desde la historia y la historia explica cualquier cosa. La democracia se justifica mientras dura, mientras resulte acorde con el fermento desde el que se nutre. En uno u otro caso, se justifica la democracia y otras cosas y, también, la democracia es susceptible de perder su justificación. Las cosas suceden de modo diferente en el caso de la FE. Esta hace de la democracia la gramática del ejercicio de la racionalidad práctica. La pretensión de «superar» la democracia se revela tan imposible con la aspiración a -hablar y- «superar» la gramática, a demostrar y «superar» la lógica $^{66}$. La FE subraya la inexcusable presencia del procedimiento en las decisiones sobre valores y destaca que tales procedimientos no son distintos de los principios que toman cuerpo en cierta idea de democracia, la democracia republicana. No

${ }^{66}$ No pasará desapercibido al lector que, en el conjunto de esta argumentación y muy particularmente en la comparación que nos lleva a afirmar que «del mismo modo que no podemos hablar sin gramática o inferir sin lógica...», existe un proceder trascendental -inevitable, por demás- y una utilización cómplice del lenguaje natural como herramienta demostrativa. Frente a ambas, quisiera invitar a la cautela. Las modernas tendencias naturalista en epistemología, filosofía de la ciencia (Giere, 1992) y, sobre todo, los resultados positivos de las ciencias cognitivas (Churchland, 1989) -acaso menos de los proclamados por sus recientes conversos, pero sin duda importantes- nos recuerdan algo bien sabido y con frecuencia olvidado por la comunidad filosófica, a saber, que hay que andar muy prevenido con ciertas invocaciones a lo que nos parece evidente, invocaciones que se amparan en un sentido común cargado de falsas teorías y-sus correspondientes- presunciones ontológicas. Tales recomendaciones de abandonar las trampas metafísicas de nuestro lenguaje, y las correspondientes críticas- desde luego absolutamente suscribibles- a los trucos de filósofos en su uso licencioso de argumentos trascendentales y de experimentos mentales demostrativos, nos han recordado que so pretexto de explorar las presunciones implícitas en la ciencia acostumbramos a introducir de rondón conceptos y preguntas imposibles arrastradas por nuestro viciado lenguaje natural (al modo como se trampea con la falsa pregunta: «si el universo es finito, ¿qué hay fuera?»).

No cabe sino elogiar tan saludable proceder. Pero, de nuevo, cautela con nuestra comparación: muy bien pudiera suceder que algún día nos comuniquemos sin lenguaje, que nos transmitamos la información conectándonos neuronalmente, que el lenguaje no esté asociado a la gramática o que las teorías no requieran proposiciones, en suma, el día en que ciertos matrimonios conceptuales que nos parecen indisolubles dejen de serio. Puede. Pero lo que es seguro es que ese día, lo que entendamos por lenguaje, gramática, comunicación o teorías -si persisten tales rótulos- será algo bien diferente de lo que hoy entendemos. De modo que nuestra argumentación se puede mantener una vez se introduce una cláusula «dada nuestra actual idea de (lenguaje, comunicación, lógica,...) no sabríamos que quiere decir...». Por lo demás, no quisiera pasar la ocasión de observar que tan razonables juicios, críticas y entusiasmos -en los que por cierto, los principales protagonistas son (ex)filósofos- que arrancan recordando que, metro a metro, la ciencia ha ido expulsando preguntas «naturales» de siempre y segando la hierba bajo los pies de los filósofos, acostumbran a hacer uso -como no puede dejar de ser, dada la naturaleza del asunto- de argumentos no menos trascendentales del tipo: «del mismo modo que el flogisto y el calórico no fueron reducidos a -explicados desde- los conceptos químicos modernos, sino que fueron abandonados, los conceptos de la psicología popular (deseos, creencias, etc.) deben abandonarse, en tanto no encuentran anclaje en la moderna neurobiología...». Cierto es que este argumento es el de los más radicales (eliminacionistas), pero no lo es menos que el uso de tales estrategias de argumentación son la moneda habitual (de hecho, precisamente por lo que afirman, desde el punto de vista de las licencias de filósofos, los eliminacionistas son los más cautos en el uso de argumentos de principio). 
hay un modo independiente de determinar unas preferencias bien formadas, una idea de buena vida, que la que cuaja en la democracia.

3. La FE captura la pertinencia de la FI y el realismo de la FH. Como destaca la FI, la democracia tiene que ver con la toma de decisiones sobre la vida colectiva. Es falaz la contraposición entre una democracia competitiva que toma decisiones y otra en la que lo importante es la autorrealización de los ciudadanos, con independencia del «para qué» de la actividad política. La autorrealización es un estado lateral que acompaña la realización de algo. Para que el individuo experimente la autorrealización es condición necesaria que su acción sirva para algo distinto de la autorrealización. Para que el individuo se autorrealice -en una actividad política $^{67}$ - se requiere que realice algo exterior a él mismo, que lo que haga tenga sentido social, que sirva para algo. Pero no es suficiente. También se requiere que la acción tenga sentido para el individuo, que éste crea en lo que hace. Sólo si sé que lo que yo hago -además de servir para algo- tiene sentido para

${ }^{67}$ En las páginas anteriores se ha insistido en que la autorrealización requiere la realización externa de algo. Esa exigencia no impide que esa realización sea privada, que, por ejemplo, un catador de vinos disfrute privadamente de su entrenada habilidad. Las actividades autorrealizadoras se oponen estrictamente tan sólo a las actividades de consumo, mientras estas últimas tienen rendimientos marginales decrecientes, las primeras, aun si al principio son costosas, andando el tiempo, y como resultado de su propio quehacer, aumentan el disfrute. Otra cosa es que la autorrealización requiera no sólo del ejercicio de la actividad, sino del buen ejercicio, del éxito en la tarea, y que éste necesite de un contexto público para su apreciación. La autoestima, que tiene mucho que ver con el negocio del buen vivir, si se requiere anclada en el mundo, requiere de los otros. Es condición necesaria, aunque no suficiente de la felicidad. Precisamente cuando no están los otros, cuando no hay «externalización» del proceso de autorrealización, es cuando aparece la patología: el genio arrogante que se alimenta desde sí mismo, la neurosis, la autodestrucción y el desprecio al mundo que acompañan con frecuencia a los caracteres geniales (Eysenck, 1995: 202-ss). 
mí, si me parece razonable, podré experimentar la autorrealización. Ahí es donde la FI encuentra problemas: para que el individuo experimente como dotada de sentido su acción se requiere que le parezca justificada. Si no tengo razones para mis preferencias, si todo da igual, que se elija lo que me gusta o no me podrá parecer más o menos conveniente, me llevará o no a lamentar el tiempo perdido en elegir, pero nada más.

La FH destacaba con justicia que la elección no es capricho, que tiene que ver con la historia. Ese apreciable realismo es también rescatado por la FE. Es cierto que no elegimos desde detrás de nosotros mismos, que nuestra biografía nos proporciona criterio, y que, en ese sentido, no todo es igual. No estamos en suspenso moral, somos nuestras valoraciones e ignorar eso es ignorar los hechos. Pero de ahí no se sigue que solo quepa resignarse a reconocer la diversidad de biografías, que no se pueda decir nada razonablemente acerca de los otros ${ }^{68}$, que cada uno (cada comunidad) esté condenado a su criterio y no quede lugar para la calibración. Con paradoja: la crítica comunitaria, que arranca diciendo que no todo es igual, deriva con facilidad en un relativismo histórico que viene a decir que todo da lo mismo, que ante la diversidad de las biografías, sólo queda la indeterminación. Por más que la FH haga lema de que «no todo es igual», lo cierto es que se ve en dificultades para asumir esa conclusión cuando se sostiene simultáneamente que existen distintas perspectivas, que no hay modo «trascendental» de compararlas y que nadie puede escapar a la suya, a su nicho cultural. No solo eso, la FH, al afirmar que son los valores sociales «densos» los que proporcionan el auténtico («sentido») criterio de evaluación, más allá de las (imposibles) preferencias de los individuos, se ve en la obligación de admitir que las gentes se pueden comprometer en acciones valiosas (con sentido) para la comunidad pero desprovistas de valor (sentido) para ellas ${ }^{69}$. Recala exactamente en el mismo problema de la FI: el individuo que no cree justificada -provista de razones- su acción difícilmente la creerá con valor (sentido).

4. Reconoce la relatividad de los puntos de partida sin derivar en el nihilismo. La FE asume que las preferencias vienen de alguna parte, que los individuos -contra la FI- no son simples sujetos que manifiestan deseos, que sus escenarios los constituyen como individuos, pero también admite un lugar para la revisión racional. Revisión que, como se vio, es garantía de que los individuos reconozcan como «dotadas de sentido a sus acciones». Sólo la racionalidad, la buena basamentación, asegura que el compromiso de uno

68 Tesis en la que coincidirían cierto comunitarismo y el «liberalismo»: el primero desde la irreductibilidad de las biografías y la imposibilidad de los criterios trascendentales; el segundo desde el «todo vale» que alimenta el problema del liberalismo y el bien. Cfr. supra nota 51.

${ }^{69}$ Las sociedades integristas disponen de un buen arsenal de pautas compartidas que para muchos de sus habitantes -particularmente las mujeres- no se experimentan como propias, no parecen «razonables». Pautas que aun cuando tienen todos los atributos de los valores sociales «densos», para proporcionar «sentido» son poco «sentidos», asumidos como propios, por sus presuntos (so)portadores. Sobre esta dificultad del comunitarismo cfr. Kymlicka (1990). 
con sus ideas o preferencias es, a la vez, eficaz y realmente sentido: sirve para resolver problemas y se muestra bien fundamentado. Intuición, gustos o intereses para la FI, biografía, dioses o lenguaje para la FH, las elecciones de los individuos carecían de razones. Vacíos de memoria o embriagados de historia tales sujetos hacían naufragar los proyectos que pretendían fundamentar: en un caso la «toma de decisiones» pierde toda relevancia, en el otro, las certidumbres de todos dejan de serlo cuando no se asientan en las certidumbres de cada uno. La FE reconoce que la inevitable diversidad de biografías compromete la relatividad del punto de partida de la vida democrática. Sin embargo, eso es cosa distinta de asumir que el punto de llegada también es «relativo». Asumir que los argumentos están condenados a la indeterminación es negar la idea misma de argumentación. En rigor, adoptar ese punto de vista equivale a afirmar que lo que se está diciendo resulta ininteligible. La pretensión de convencer conlleva implícita la confianza en que el punto de partida no es «relativo».

\section{Para concluir}

El repaso anterior ha permitido, en primer lugar, reconocer la naturaleza irresoluble del PFD: se manejan distintas teorías de la democracia y de fundamentación. Enfrentadas a problemas diferentes y con diferentes maneras de abordarlos las tres perspectivas resultan inconmensurables. No hay un rasero compartido para calibrarlas. Podría parecer que ese juicio no resulta compatible con la defensa de la FE. La paradoja se explica desde lo que exactamente se afirma, a saber, que únicamente la FE y la idea de democracia que la acompaña tienen que ver realmente con una fundamentación moral, que cuando se trata de los asuntos de racionalidad práctica tan solo la democracia republicana resulta pertinente. También se podría haber mostrado que desde el punto de vista explicativo la FH está en la línea correcta. Sencillamente, las distintas perspectivas están en distintos asuntos.

La primera idea de democracia, como simple procedimiento para agregar preferencias, resulta adecuada en determinados escenarios. Si de lo que se trata es de decidir de qué color pintar la fachada de un edificio no parece mal método votar sin más. La elección no parece requerir demasiadas razones ${ }^{70}$. Otro tanto sucede cuando hay que elegir entre intereses en estado puro y no hay posibilidad de buscar equilibrios compensadores. Si en la escalera hay una mayoría de zurdos, a la hora de colocar los interruptores del

${ }^{70} \mathrm{La}$ reserva tiene que ver con el reconocimiento de que caben consideraciones ulteriores en la decisión del color; una combinación de colores en una pared produce ciertas sensaciones o impresiones; un coche blanco resulta particularmente visible y tiene una probabilidad de accidentes más baja que uno de otro color: etc. En estos casos las preferencias tienen alguna base informativa y los juicios se pueden fundamentar hasta cierto punto. 
ascensor resulta razonable colocarlos en el lado izquierdo ${ }^{71}$. Todo eso tiene poco que ver con la moral y de hecho no se necesita la democracia para tomar decisiones que maximicen el bienestar $^{72}$. Frente a cierto panmoralismo fundamentalista, que equipara elección a decisión moral, es buena cosa reconocer que no todas las elecciones son iguales, que no todas son elecciones morales, que no es lo mismo decidir un color para pintar la fachada de un edificio que decidir acerca de cómo distribuir la renta. La FI equipara en dirección contraria: todas las decisiones son iguales porque ninguna tiene que ver con consideraciones morales razonadas.

La FI al trivializar las preferencias trivializa las elecciones e iguala las otras elecciones a la elección de colores. Ninguna parece requerir razones, las preferencias privadas (prepolíticas) constituyen palabra última. Una vez la elección se realiza desde ahí, la democracia se reduce a la aplicación de una -inevitablemente ${ }^{73}$ - arbitraria regla de elección a unas preferencias desprovistas de razones. Con arbitrariedad de voluntades y arbitrariedad de procedimientos, en el límite, la democracia pierde cualquier posibilidad de cimiento racional. Cuando no hay razones para preferir una cosa a otra, cuando todo da lo mismo, la idea de elección o la defensa de valores como la libertad -de «elección»- pierden todo significado reconocible. Así las cosas, esta idea de democracia arrastra como consecuencia la inevitable paradoja liberal, el llamado «problema del liberalismo y el bien», la dificultad para conciliar la imparcialidad respecto a las distintas ideas con la defensa

71 También aquí habría lugar para la reserva. En el trasfondo se está presumiendo algún tipo de igualdad que podría ser objeto de discusión. Si, p.e., los zurdos (cuya supervivencia en un mundo construido por los diestros constituye un conocido enigma para la teoría evolutiva), como consecuencia de un proceso de «adaptación» hubiesen desarrollado una mayor destreza con la mano derecha que los diestros con la izquierda, podría pensarse en colocar los interruptores en el lado derecho. La cosa está en que, también a propósito de gustos e intereses, hay lugar para la formación deliberativa de preferencias y para que en la deliberación aparezcan consideraciones morales. (Obviamente, en el ejemplo, si no existieran costos, se podrían poner algunos días a un lado y otros al otro).

72 Cierto es que algo ayudan las reglas que aseguran algún tipo de igualdad (cfr. nota siguiente), al garantizar que todas las voces se tienen en cuenta. Pero también cabe la hipótesis del dictador ilustrado y benevolente; quien, por cierto, también asegura la igualdad del poder político: todos tienen igual poder, esto es, ninguno. Por lo demás ya sabemos que una cosa es que se conozcan las preferencias y otra que se satisfagan. En algún sentido lo primero es condición de lo segundo, pero lo que realmente interesa a la FI -al utilitarismo p.e.- es lo segundo. Para la FI no hay problema mientras se maximice ese impreciso objetivo llamado «utilidad» o cualquier otro, aun sin democracia.

73 Inevitable en el sentido de que, cuando la elección se realiza entre pares de alternativas, hay bastantes reglas de elección (mayoría, pluralidad, Condorcet, Borda, votación exhaustiva, aprobación, etc.) compatibles con elementales principios de igualdad que aplicadas a un mismo conjunto de preferencias conducen a resultados diferentes. Por supuesto que otras reglas -una que, p.e. proporcionase a los licenciados en economía tres votos y ninguno a filósofos violarían la igualdad y, de entrada, no resultarían aceptables. Pero lo que ahora se quiere destacar es que, entre las aceptables, no hay criterios de decisión indiscutibles. 
de las propias, dificultad que convierte al ideario liberal en un triste relativismo sin fuerza moral, incapaz de proporcionar razones en favor de la libertad o de descalificar idearios racistas.

Los problemas de la perspectiva instrumental estaban bien señalados por el comunitarismo. Elegir requiere perspectiva, prioridades, preferencias que se construyen socialmente y que dotan de identidad a los individuos. La FI presume un sujeto imposible, un sujeto anterior a sus preferencias, un yo que elige desde ninguna parte. El hombre es «lo que quiere» y lo que quiere tiene que ver con su historia, con una red cultural que proporciona criterio a las elecciones. Y no hay más: nadie puede saltar por encima de su sombra y nadie puede escapar a sí mismo. Si no hay punto de referencia incondicional, se revela una ilusión -deudora ella misma de la historia- la aspiración a una fundamentación trascendental.

Pero también hay dudas acerca de si la FH es una genuina fundamentación. Reconocer que estamos donde estamos por la historia, que estamos «enzarzados en mundo», es mantenerse en el plano explicativo. Pero explicar nuestras elecciones no es justificarlas. Afirmar que no hay modo de escapar a una identidad constituida socialmente equivale a condenar el proyecto fundamentador por la vía más rápida. A los individuos sólo les cabe (re)conocerse su auténtica identidad histórica, no evaluarla, no revisarla. No hay, pues, lugar para la genuina evaluación. Las elecciones son simples ficciones que confirman lo que es su punto de partida. La idea misma de racionalidad práctica se revela un sueño, como Dios, el alma y otras ilusiones cuya existencia se agota en nosotros mismos, en nuestra capacidad para construir patrañas que nos consuelan y entretienen.

La perspectiva epistémica es la única que reconoce el PFD sin desatender los argumentos de la FH. Rescata el buen tino de la crítica comunitaria sin concluir que las preferencias están desprovistas de calidad moral. Admite que la elección se hace desde alguna parte sin verse en la obligación de creer que no podemos escapar a nuestras anteojeras, a nuestro presente.

Ese reconocimiento de la crítica comunitaria -que no conlleva, como sucede con la $\mathrm{FH}$, negar el PFD se deja ver en la solvencia de la FE para escapar a dificultades presente en enfoques normativos- liberalismo y comunitarismo- estrechamente asociados a las FI y FH, dificultades que el PFD ha mostrado con particular notoriedad: la paradoja liberal y la paradoja nihilista, respectivamente. La primera tenía que ver con la incapacidad liberal para defender la libertad, empeño que no resulta sencillo cuando se asume que todo -y por tanto la libertad- vale lo mismo. La paradoja nihilista, como ya se vio, aparecía al contemplar a la sociedad como proporcionadora de sentido, de identidad a los individuos, y admitir a la vez que los individuos puedan no encontrar «sentido» (razones) a sus acciones. Pues bien, la FE rescata la pluralidad liberal sin incurrir en la indeterminación y también reconoce la corrección de la crítica comunitarista sin negar la pluralidad: 
1. La FE incorpora la crítica comunitaria al sujeto trascendental y al indeterminismo liberal: no hay sujeto sin biografía y las preferencias son fundamentalmente materia social. Pero a partir de ahí añade: precisamente ese carácter social de las preferencias obliga a reconocer la posibilidad de su revisión. Eso sí, para ello se requiere que el escenario adopte cierta forma, la democracia republicana. Un escenario en donde las preferencias se forman públicamente, en la ciudad. Las preferencias son materia de discusión, y quien dice discusión dice posibilidad de revisión del juicio y, por tanto, de la identidad. El punto de partida es el reconocimiento, impuesto por la idea misma de argumentación pública, de la posibilidad de modificar las opiniones. A partir de ahí la argumentación se muestra compacta. Justamente por no existir sujetos por encima de sus biografías, de sus preferencias, la revisión de éstas implica la posibilidad de revisar las identidades. Se reconoce la crítica de la $\mathrm{FH}$, los individuos no son distintos de sus querencias, no son impermeables al tiempo; pero sin incurrir en las paradojas nihilistas del comunitarismo. Los individuos están en condiciones de sentirse parte de la ciudad porque están convencidamente en la ciudad. La democracia republicana conforma una voluntad compartida que no es la foto fija de una identidad colectiva que -a diferencia de la democracia comunitaria- no se sabe cómo podría cambiar, habida cuenta de que encuentra en los individuos, en sus preferencias, el reflejo que ella misma proyecta.

2. La confianza en la posibilidad de argumentar y revisar públicamente las ideas es el fundamento que permite hacer compatibles sin ortopedia el reconocimiento de la pluralidad (liberal) de ideas acerca de cómo vivir con el reconocimiento de que una puede ser superior a otras. Se argumenta porque se confía en mostrar razones en favor de ciertas ideas. A todas las preferencias se les garantiza la presunción del mismo valor: ese es el buen sentido del respeto y la tolerancia democráticos. Pero eso es cosa distinta de que tengan el mismo valor. El respeto será veraz desde la seguridad de que todas las preferencias podrán ser sometidas al foro, a la discusión y ésta, a su vez, será real desde la convicción de que hay la posibilidad de mostrar que no todo es lo mismo. Que todas las ideas de bien sean igualmente tratadas no equivale a sostener que todas valen igual. Es porque no todas valen igual por lo que todas han de disponer de los mismos derechos. La democracia se justifica como un procedimiento para determinar las mejores ideas y el procedimiento requiere que todas las ideas se puedan expresar. Y eso es así porque no hay un modo de determinar las mejores razones que no pase por las condiciones de autonomía que cristalizan en la democracia. La modificación de las ideas de un «equivocado» no vendrá de una iluminación, sino de la propia revisión -de la propia elección- razonada de sus juicios. La idea de buena vida contiene el proceso de su determinación. No se trata sólo de ciertas creencias acerca del cómo vivir, sino también y sobre todo de un modo de justificar esas creencias, de una manera de determinarlas. La buena vida es ejercicio de racionalidad y, en ese sentido, una idea 
prioritariamente metódica, de procedimiento, más que substantiva, que los valores «densos» de la FH; y no hay otra manera de determinar las buenas creencias que aquella que toma cuerpo en las condiciones de autonomía asociadas a la democracia republicana. Del mismo modo que no hay -modo de conocer- una verdad por detrás de la ciencia, que no hay otra «verdad» que la que se conoce a través de los procedimientos correctos y que el único modo de acercarse a su conocimiento es el que cristaliza en las maneras de la ciencia; tampoco habría una idea de buena vida «revelada», independiente de la buena formación de esa idea.

3. La FE evita el irrealismo de las elecciones instrumentales sin concluir -con la FH- que son ficciones confirmatorias del ser social. Las propias condiciones de la racionalidad práctica quiebran la falaz inferencia de la FH que del reconocimiento de que los individuos están provistos de una identidad constituida socialmente deriva el juicio de que la identidad es no sólo el punto de partida de las elecciones sino también su horizonte, su punto de llegada. Recuérdese la comparación. Por supuesto que estamos instalados en un punto de vista, pero, precisamente en virtud del lenguaje (la ciencia y la racionalidad) podemos escapar a biografias de especie, podemos escapar a constricciones perceptuales, a la física aristotélica, a la geometría euclidiana y al espectro detectable neurosensorialmente; constricciones que, no se olvide, están hondamente -tan irremediables como la biología- afincadas en nosotros, constricciones que son muy funcionales -sirven para sobrevivir- desde una perspectiva evolutiva. Nada puede estar más instalado y nada puede resultar más útil a la hora de -permítase esta última licencia- proporcionar «sentido». Y sin embargo nuestro horizonte racional no se agota ahí, hay posibilidad de escapar. No parece que se pueda encontrar mejor prueba de que es posible obtener certidumbres sin ahogarse en certidumbres.

\section{REFERENCIAS}

Ackerman, B. (1980), Social Justice in the Liberal State, New Haven: Yale U.P. -(1991), We the People, Harvard: Belnap, Harvard U.P.

Ackerman, B.; Rosenkrantz, C. (1991), «Tres concepciones de la democracia constitucional», Centro de Estudios institucionales de Buenos Aires, Fundamento y alcance del Control de constitucionalidad, Madrid: Centro de Estudios Constitucionales.

Ainslie, G. (1992), Picoeconomics, Cambridge: Cambridge U.P.

Anderson, E. (1993), Value in Ethics and Economics, Harvard: Harvard U.P.

Annas, J. (1993), The Morality of Happiness, Oxford: Oxford U.P.

Arendt, H, (1959), The Human Condition, N. York: Doubleday.

-(1973), On Revolution, Harmondworth: Pelican Books.

Arrow, K. (1951), Social Choices and Individual values, New York: Willey.

Barber, B. (1984), Strong Democracy, Berkeley: University of California Press. 
Barry, B. (1970), Sociologists, Economics and Democracy, London: Macmillan.

Beitzm, Ch. (1989), Political Equality, Princeton: Princeton U.P.

Bell, D. (1993), Comunitarianism and its Critics, Oxford: Oxford U.P.

Bothamley, J. (1993), Dictionary of Theories, London: Gale.

Boyd, R. (1988), «How to be a Moral Realist», G. Sayre-McCord (ed.), Essays on Moral Realism, Ithaca: Cornell U.P.

Buchanan, J. Tullock, G. (1962), The Calculus of Consensus, An Arbor: University of Michigan Press.

Chan, J., Miller, D. ((1991), «Elster on Self-realization in Politics: A Critical Note», Ethics, 102. Christiano, Th. (1993), «Social Choice and Democracy», Coop., D., Hampton, J., Roemer, J. (edts.), The Idea of Democracy, Cambridge: Cambridge U.P.

Churchland, P. (1989), A Neurocomputational Perspective, The MIT Press: Harvard. -(1995), The Engine of Reason. The Seat of the Soul, Harvard: The MIT Press.

Cohen, J. (1986), «An Epistemic Conception of Democracy», Ethics, 97.

-(1989), «Deliberation and Democratic Legitimacy», Hamlin, A., Pettit, Ph. (eds.), The Good Polity, Oxford: Blakwell.

-(1993), An Essay on Belief and Acceptance, Oxford: Clarendon Press.

Coleman, J.; Ferejhon, J. (1986); «Democracy and Social Choice», Ethics, 1.

Dahl, R. (1956), Preface to Democratic Theory, Chicago: Chicago U.P.

-(1989), Democracy and its Critics, New Haven: Yale U.P.

Darwall, S. (1988), «Self-Deception, Autonomy and Moral Constitution», en McLaughlin, Rorty, A. (edts.), Perspectives on Self-Deception, Berkeley: University of California Press.

Dennet, D. (1991), «Two Contrats: folk craft versus folk science, and belief versus opinion», en Greenwood, J. (edt.), The Future of Folk Psychology, Cambridge: Cambridge U.P.

Dietz, M. (1985), «Citizenship with a Feminist Aace», Political Theory, 13, 1.

Doménech, A. (1989), De la ética a la politica, Barcelona: Crítica.

-(1993), «... y fraternidad», Isegoría, 7.

-(1995), «Individualismo ético e identidad personal», R. Aramago, J. Muguerza y A. Valdecantos (comp.), El individuo y la historia, Barcelona: Paidós.

Douglas, R.; Mara, G.; Richardson, H.; (edts.) (1990), Liberalism and the Good, New York: Roultlege.

Downs, A. (1957), An Economics Theory of Democracy, New York: Harper and Row.

Dunleavy, R, Margetts, H. (1995), «Belief in Democratic Myth», en K. Dowding, D.

King (edts.), Preferences, Institucions and Rational Choice, Oxford: Clarendon.

Dunn, J. (edt.) (1993), Democracy. The Unfinished Journey. 508 BC to AD 1993, Oxford: Oxford U.P.

Dworkin, R. (1990). «Equality Democracy and Constitution», Alberta Law Review, 2.

Elshtain, J. (1981), Public Man, Private Woman, Princeton: Princeton U.P.

Elster, J. (1986a) «The Market and the Forum», Hylland, A.,; Eister, J. (edts.), Foundations of Social Choice Theory, Cambridge: Cambridge U.P

-(1986b) «Self-realitation in work and politics», Social Philosophy and Policy, 3, 2.

-(1994), «Argumenter et négocier dans deux assembleés constituantes», Revue Française de Science Politique, 44, 2. 
-(1995), «The Empirical Study of Justice», D. Miller, M. Walzer (edts.), Pluralism, Justice and Equality, Oxford: Oxford U.P.

Elster, J.; Slagstad, R. (edts,), Constitucionalism and Democracy, Cambridge: Cambridge U.P.

Elster, J.; Roemer, J. (edts.), (1991), Interpersonal Comparations of Well-Being, Cambridge: Cambridge U.P.

Estlund, D., (1993), «Making truth sale for Democracy», Coop, D., Hampton, J., Rioemer, J. (edts.), The idea of Democracy, Cambridge: Cambridge U.P.

Eysenck, H. (1995), Genius, Cambridge: Cambridge U.P.

Ferejhon, J. (1993), «Must preferences be respected in a democracy?», Coop, D., Hampton, J., Roemer, J. (edts.), The idea of Democracy, Cambridge: Cambridge U.P.

Finley, M. (1973), Democracy, Ancient and Modern, New Brunswick: Rutgers U.P.

Fishkin, J. (1991), Democracy and Deliberation, New Haven: Yale U.P.

Flanagan, O. (1991), Varieties of Moral Personality, Cambridge: Harvard U.P.

Foot, Ph. (1978), Virtue and Vices, Berkeley: University of California Press.

Gargarella, R. (1993), Representation and Irrationality The Philosophical Foundations of Representative System, Tesis Doctoral, University of Chicago.

-(1995), Nos los representantes. Crítica a los fundamentos del sistema representativo, CIEPP, Niño y Dávila: Buenos Aires.

Garzón Valdés, E. (1994), «Instituciones Suicidas», Isegoría.

Gauchet, M.; Manent, R; Rosanvallon, P. (1993), Situation de la Démocratie, Paris: Gallinard, Le Seuil.

Giere, R. (edt.), (1992), Cognitive Models of Science, University of Minnesotta Press: Minneapolis.

Gutmann, A. (1993), Democracy, en R. Goodin, Ph. Pettit (edts.), A Companion to Contemporary Political Philosophy, Oxford: Blackwell.

Haak, S. (1993), Evidence and Inquiry, Oxford: Blackwell.

Habermas, J. (1988), «Discoursive Ethics», Reconstruction and Interpretation in Social Sciences, Harvard: The MIT Press.

-(1992), «Tres modelos de democracia», Debats, 39.

Hardin, R., (1993), «Public Choice versus democracy», Coop, D., Hampton, J., Roemer, J. (edts.), The idea of Democracy, Cambridge: Cambridge U.P.

Haussman, D. (1995), «The Impossibility of Interpersonal Utility Comparasions». Mind, 415.

Held, D. (1987), Models of Democracy, Cambridge, Polity.

Ingram, D. (1995), Reason, History and Politics, Albany: SUNY.

Kahan, A. (1993), Aristocratic Liberalism, Oxford: Oxford U.P.

Kagan, S. (1989), The Limits of Morality, Oxford: Oxford U.P.

Kirkham, R. (1992), Theories of Thurt, The MIT Press: Harvard.

Kymlicka, W. (1988), «Liberalism and Comunitarism», Canadian Journal of Philosophy, 18.

Kymlicka, W. (1990), Contemporany Political Philosophy, Oxford: Oxford U.P.

Lewis, D. (1983), «How to Define Theoretical Terms», Philosophical Papers, col. 1., Oxford: Oxford U.P.

McIntyre, A. (1983), «Moral Arguments and Social Contexts», Journal of Philosophy, 80. 
Macpherson, c. b. (1980), The Life and Times of Liberal Democracy, Oxford: Oxford U.P. Madison, J. (1961), an Hamilton, A.; Madison, J.; Hay, J. The Federalist Papers, N. York: New American Library (e.o. 1787).

Manin, B. (1987), «On Legitimacy and Political Deliberation», Political Theory.

-(1991), «Métamorphoses du gouvernement représentatif» (manuscrito), University of Chicago. -(1995), Principes du goubernement Representative, Paris: Calmann-Lévy.

May, K. (1952), «A Setof Independent Necesary and Sufficient Conditions for Simple Mayority Decision». Econometrica, 20.

McCloskey, M. (1983), «Intuitive Physics», Scentific American, 284/4.

Mill. J. (1978), «Essay on Gobernment», en J. Lively, J. Rees (edts.), Utilitarian Logic and Politics, Oxford: Oxford U.P. (e.o. 1818).

Mill, J. S. (1956), Considerations on Representative Government, Indianapolis: Bobbs-Merrill (e.o. 1861).

Miller, D. (1989), Market, State and Community, Oxford: Clarendon Press.

-(1993), «Deliberative Democracy and Social Choice», en D. Held (edt.), Prospects for Democracy, Polity: Cambridge.

Miller, F. (1995); Nature, Justice and Rights in Aristotle's Politics, Oxford: Clarendon Press. Mueller, D. (1989), Public Choice II, Cambridge: Cambridge U.P.

Nelson, W. (1980), On Justifying Democracy, London: Routhledge, 1980.

Niinluoto, I. (1984), Is science Progressive? Drodrecht: Reidel.

Nino, C. (1989), Ética y derechos humanos, Barcelona: Ariel.

-(1991), «El presidencialismo argentino y las concepciones de la democracia», Centro de Estudios Institucionales (CEI), Buenos Aires.

Nino, C.; Rosenkrantz, C. (1991), «Polémica sobre la fundamentación de la democracia», Doxa, 10 .

Nussbaum, M. (1990), Love's knowledge, Oxford: Oxford U.P.

Offe, C. (1992), La gestión política, Madrid: Ministerio de trabajo.

Ostrogorski, M. (1993), La démocratie et les partis politiques, Paris: Fayard (e.o. 1903).

Ovejero, F. (1994), Mercado, ética y economía, Barcelona: Icaria/Fuhem

-(1994a), La Quimera fértil, Barcelona: Icaria.

-(1995a), «El salario universal garantizado y los requisitos de los proyectos emancipatorios», R. Lo Voulo (edt.) Contra la exclusión, Miño y Dávila Editores: Buenos Aires.

-(1995b), «Democracia y ética ecológica», A. Vercher, E. Peris (edts.), El papel de los consumidores en la protección ambiental, Fundación CAM: Valencia.

-(1995c), «Los tres comunitarismos», Seminario de Metodología de las CC SS, Universidad de Barcelona.

Palmarini, M. (1995), Los túneles de la mente, Barcelona: Crítica.

Paterman, C. (1970), Participation and Democratic Theory, Cambridge: Cambridge U.P.

Pettit, P. (1989), «The freedom of the city: a republical ideal», en Hamlin, A., Pettit, Ph. (eds.), The Good Polity, Oxford: Oxford: Blakwell.

Phillips, D. (1993), Looking Backard, Princeton: Princeton U.P. 
Pratkanis, A., Aronson, E. (1992), Age of Propaganda, Freeman and Company: N. York.

Ralws, J. (1993), Political Liberalism, New York: Columbia U.P.

Rescher, N. (1973), The Coherence Theory of Truth, Oxford: Oxford U.P.

-(1984), The Limits of Science, Berkeley: California U.P.

-(1987), Ethical Idealism, Berkeley: California U.P.

-(1993) Pluralism, Oxford: Clarendon.

Riker, W. (1982), Liberalism against Populism, S. Francisco: Freeman.

Rorty, A. (1980), Essays on Aristotle's Ethics, Berkeley: University of California Press.

Rorty, A. (1983), «Postmodern Burgeois Liberalism», The Journal of Philosophy.

Sandel, M. (1982), Liberalism and the Limits of Justice, Cambridge U.P.

Scheffler, S. (edt.), Consecuentialism and its Critics, Oxford: Oxford U.P.

Schmidtz, D. (1990), «Justifying The State», Ethics, 101.

Schumpeter, J. (1976), Capitalism, Socialism and Democracy, New York: Harper (e.o. 1949).

Sen, A. (1991), «Utility», Economics and Philosophy, 7.

Sen, A.; Williarns, B.; (edts), (1982), Utilitarianism and Beyond, Cambridge: Cambridge U.P. Sherman, N. (1989), The Fabric of Character, Oxford: Clarendon.

Sieyes, E. (1993), Estudios políticos, México: FCE.

Singer, P. (1973), Democracy and Disobedience, Oxford: Oxford U.P.

-(1979), Practical Ethics, Cambridge: Cambridge U.P.

Strauss, L. (1964), The City and Man, Chicago: R. McNally.

Sunstein, C. (1989), «Beyond the republican revival». The Yale Law Review, 97.

-(1991), «Preferences and Politics», Philosophy and Public Affairs, 1.

-(1993), «Democracy and shifting prederences», Coop, D., Hampton, J., Roemer, J. (edts.), The idea of Democracy, Cambridge: Cambridge U.P.

Sutherland, S. (1994), Irrationality, New Brunswick: Rutgers U.P.

Taylor, Ch. (1995), «Liberal-Comunitarian Debate», «Liberal Politics and the Public Sphere», en Philosophical Arguments, Harvard: Harvard U.P.

Unger, R. (1987), Politics, Cambridge: Cambridge U.P.

Van Parijs, Ph. (1995), Real Freedom for All, Oxford: Clarendom Press.

-(1981) «Philosophy and Democracy», Political Theory, 3.

Walzer, M. (1990), «The Comunitarian Critique of Liberalism», Political Theory, 1.

Wittman, D. (1989), «Why Democraties Produces Efficient Result», Journal of Political Economy, 6.

Wriglestorth, John, L. (1985), Libertarian conflicts in social choice, Cambridge: Cambridge U.P. 
